NIST Technical Note 2172

\title{
A Review of Community Resilience Frameworks and Assessment Tools: An Annotated Bibliography
}

\author{
Emily H. Walpole \\ Jarrod Loerzel \\ Maria Dillard
}

This publication is available free of charge from: https://doi.org/10.6028/NIST.TN.2172

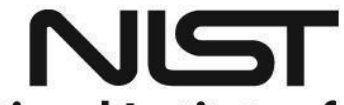

National Institute of Standards and Technology U.S. Department of Commerce 
NIST Technical Note 2172

\title{
A Review of Community Resilience Frameworks and Assessment Tools: An Annotated Bibliography
}

\author{
Emily H. Walpole \\ Jarrod Loerzel \\ Maria Dillard \\ Materials and Structural Systems Division \\ Engineering Laboratory
}

This publication is available free of charge from: https://doi.org/10.6028/NIST.TN.2172

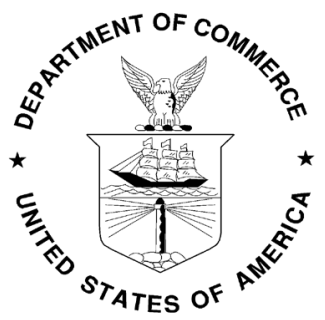

U.S. Department of Commerce Gina M. Raimondo, Secretary

National Institute of Standards and Technology James K. Olthoff, Performing the Non-Exclusive Functions and Duties of the Under Secretary of Commerce for Standards and Technology \& Director, National Institute of Standards and Technology 
Certain commercial entities, equipment, or materials may be identified in this document in order to describe an experimental procedure or concept adequately. Such identification is not intended to imply recommendation or endorsement by the National Institute of Standards and Technology, nor is it intended to imply that the entities, materials, or equipment are necessarily the best available for the purpose.

National Institute of Standards and Technology Technical Note 2172

Natl. Inst. Stand. Technol. Tech. Note 2172, 59 pages (August 2021) CODEN: NTNOEF

This publication is available free of charge from: https://doi.org/10.6028/NIST.TN.2172 


\begin{abstract}
Community resilience is a topic of increasing interest in public policy and planning, although effective implementation will require an in-depth theoretical understanding of the concept, as well as the ability to measure changes in resilience over time. In recent years numerous frameworks have been developed to operationalize community resilience, utilizing different theoretical and methodological approaches. As part of an effort to systematically document and compare existing frameworks, 56 community resilience frameworks and assessment tools were selected for further analysis, resulting in the NIST Resilience Indicator Inventory. This annotated bibliography is intended to achieve two main objectives: 1) provide context to the primary sources used in the Resilience Indicator Inventory dataset, and 2) summarize previous work in community resilience measurement as a resource for future planning and research. Work in this area will inform NIST's ongoing efforts in resilience metrology, including facilitating the development of a theoretically and empirically based method of community-scale resilience measurement.
\end{abstract}

Keywords: Community resilience; assessment methodologies; indicators; metrics; measurement; framework 


\section{Table of Contents}

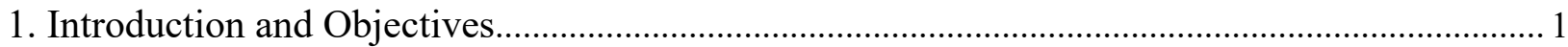

2. Inventory Article Selection and Analysis Methods....................................................................... 2

3. Annotated Bibliography of Resilience Frameworks and Assessment Tools ............................... 4

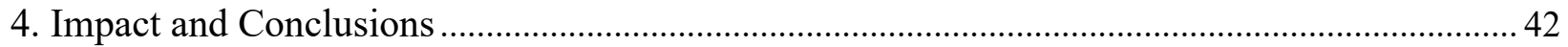

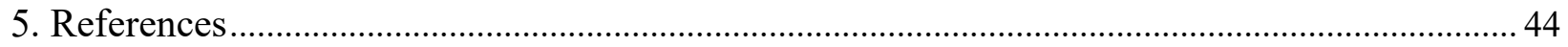

\section{Annotated Bibliography Table of Contents}

1. ARUP International Development (2016). "City Resilience Index: Understanding and Measuring City Resilience." London, UK. [ARUP - city] .......................................................... 4

2. ARUP International Development and International Federation of Red Cross and Red Crescent Societies (2011). "Characteristics of a Safe and Resilient Community: Community Based Disaster Risk Reduction Study." Geneva, Switzerland, International Federation of Red Cross and Red

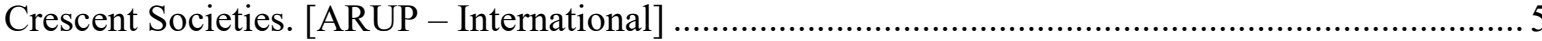

3. Bates, F. L. and W. G. Peacock (1992). "Measuring Disaster Impact on Household Living Conditions: The Domestic Assets Approach." International Journal of Mass Emergencies and Disasters 10: 133-160. [Domestic Assets Index]

4. Belcher, J.C. (1972). “A cross-cultural household level-of-living scale.” Rural Sociology, 37(2), p.208. [Level-of-Living Scale]

5. Bene, C., T. Frankenberger, M. Langworthy, M. Mueller and S. Martin (2016). "The Influence of Subjective and Psycho-social Factors on People's Resilience: Conceptual Framework and Empirical Evidence." Technical Report Series No. 2: Strengthening the Evidence Base for Resilience in the Horn of Africa, A joint International Livestock Research Institute (ILRI) and TANGO International publication. [Psycho-social Factor on People's Resilience] 7

6. Berkes, F. and C. S. Seixas (2005). "Building Resilience in Lagoon Social-Ecological Systems: A Local-level Perspective." Ecosystems 8: 967-974. [Lagoon SES]

7. Brooks, N., S. Anderson, I. Burton, S. Fisher, N. Rai and I. Tellam (2013). "An Operational Framework for Tracking Adaptation and Measuring Development (TAMD)." IIED Climate Change Working Paper Series: Climate Change Working Paper No. 5. London, UK. [TAMD (Tracking Adaptation and Measuring Development)].

8. Canadian Centre for Community Renewal (2000). "The Community Resilience Manual: A Resource for Rural Recovery \& Renewal.” British Columbia, Canada, Canadian Centre for Community Renewal. [CR Manual]

9. Canterbury District Health Board (2016). "Canterbury Wellbeing Index 2016.” Christchurch, New Zealand. [Canterbury Wellbeing Index].

10. Community and Regional Resilience Institute (2011). "Community Resilience System Initiative (CRSI) Steering Committee final report: A roadmap to increased community resilience." Community and Regional Resilience Institute. [CARRI CRS] 10 
11. Cardona, O. (2005). "Indicators of disaster risk and risk management: Main technical report." Washington, DC. Inter-American Development Bank.[Disaster-Deficit Index (DDI)] 10

12. CGIAR Research Program on Water Land and Ecosystems (WLE) (2014). "Ecosystem Services and Resilience Framework." Colombo, Sri Lanka, CGIAR Research Program on Water, Land and Ecosystems, International Water Management Institute (IWMI). [CGIAR]

13. Chandra, A., J. Acosta, S. Stern, L. Uscher-Pines, M. V. Williams, D. Yeung, J. Garnett and L. S. Meredith (2011). "Building Community Resilience to Disasters: A Way Forward to Enhance National Health Security." Santa Monica, CA, RAND Corporation with sponsorship by the U.S. Department of Health and Human Services. [BCRD].

14. Choptiany, J., B. Graub, S. Phillips, D. Colozza and J. Dixon (2015). "Self-Evaluation and Holistic Assessment of Climate Resilience of Farmers and Pastoralists (SHARP)." Rome, Italy, Food and Agriculture Organization of the United Nations (FAO). [SHARP]....

15. Constas, M. A. and C. B. Barrett (2013). "Principles of Resilience Measurement for Food Insecurity: Metrics, Mechanisms, and Implementation Issues." Expert Consultation on Resilience Measurement Related to Food Security. Rome, Italy, Food and Agricultural Organization and World Food Program. [Resilience Measurement for Food Insecurity] 13

16. Cutter, S. L., K. D. Ash and C. T. Emrich (2014). "The Geographies of Community Disaster Resilience." Global Environmental Change 29: 65-77. [BRIC].....

17. Cutter, S. L., B. J. Boruff and W. L. Shirley (2003). "Social Vulnerability to Environmental Hazards (SoVI)." SOCIAL SCIENCE QUARTERLY - Southwestern Social Science Association 84(2): 242-261. [SoVi]

18. DFID-funded International Climate Fund (ICF) (2014). "Methodology for Reporting Against KPI 4 - Number of People Whose Resilience Has Been Improved as a Result of Project Support." [BRACED]

19. Dillard, M. K., T. L. Goedeke, S. Lovelace and A. Orthmeyer (2013). "Monitoring Well-being and Changing Environmental Conditions in Coastal Communities: Development of an Assessment Method." NOAA Technical Memorandum NOS NCCOS 174. Silver Spring, MD, NOAA National Centers for Coastal Ocean Science (NCCOS). [NOAA Community well-being]...

20. Elasha, B. O., N. G. Elhassan, H. Ahmed and S. Zakieldin (2005). "Sustainable livelihood approach for assessing community resilience to climate change: case studies from Sudan (AIACC Working Paper No. 17 August 2005)." Assessments of Impacts and Adaptations of Climate Change (AIACC). [AIACC Sustainable livelihood].

22. Fisher, R.E., Bassett, G.W., Buehring, W.A., Collins, M.J., Dickinson, D.C., Eaton, L.K., Haffenden, R.A., Hussar, N.E., Klett, M.S., Lawlor, M.A. and Millier, D.J. (2010). "Constructing a resilience index for the enhanced critical infrastructure protection program (No. ANL/DIS-10-9)." Argonne National Lab (ANL), Argonne, IL, Decision and Information Sciences. [Resilience Index]

23. Frankenberger, T., T. Spangler, S. Nelson and M. Langworthy (2012). "Enhancing Resilience to Food Security Shocks in Africa." TANGO International. [TANGO] .... 
24. Hegney, D., H. Ross, P. Baker, C. Rogers-Clark, C. King, E. Buikstra, A. Watson-Luke, K. McLachlan and L. Stallard (2008). "Building Resilience in Rural Communities: Toolkit." Toowoomba, Queensland, Australia, University of Queensland and University of Southern Queensland. [Rural Communities Toolkit]

25. Institute of Governmental Studies: The University of California Berkeley (2017). "Resilience Capacity Index" (RCI). Building Resilient Regions. Retrieved 8/7/2017, from http://brr.berkeley.edu/rci/. [RCI] .....

26. Inter-Agency Standing Committee (2005). "IASC In-Country Team Self-Assessment Tool for Natural Disaster Response Preparedness." [IASC-NDRP].

27. Keating, A., K. Campbell, R. Mechler, E. Michel-Kerjan, J. Mochizuki, H. Kunreuther, J. Bayer, S. Hanger, I. McCallum, L. See, K. Willigies, A. Atreya, W. Botzen, B. Collier, J. Czajkowski, S. Hochrainer and C. Egan (2014). "Operationalizing Resilience against Natural Disaster Risk: Opportunities, Barriers, and a Way Forward.” Zurich, Switzerland, Zurich Flood Resilience Alliance. [Zurich Flood Resilience Alliance].

28. Mayunga, J. S. (2007). "Understanding and Applying the Concept of Community Disaster Resilience: A capital-based approach." Summer academy for social vulnerability and resilience building, 1(1), 1-16. [Capital-Based CDR] .

29. Miles, S. B. and S. E. Chang (2011). "ResilUS: A Community Based Disaster Resilience Model." Cartography and Geographic Information Science 38(1): 5-21. [ResilUS]

30. Miller, K. K., A. Johnson and B. Dabson (2016). "WORKING PAPER IPP/071: Measuring Resilience and Vulnerability in U.S. Counties." University of Missouri Institute of Public Policy: Harry S Truman School of Public Affairs. [MRV].

31. National Preparedness Training Center - University of Hawaii (2011). "Coastal Community Resilience: Building Resilience from the Inside Out. (CCR).” FEMA, US Department of Homeland Security National Training and Education Division: 317-333. [CCR].

32. Norris, F. H., S. P. Stevens, B. Pfefferbaum, K. F. Wyche and R. L. Pfefferbaum (2007).

"Community Resilience as a Metaphor, Theory, Set of Capacities, and Strategy for Disaster Readiness." American Journal of Community Psychology 41: 127-150. [Community Resilience and Disaster Readiness]

33. O'Connell, D., Walker, B., Abel, N., Grigg, N. (2015). "The Resilience, Adaptation and Transformation Assessment Framework: From Theory to Application." Commissioned by the Scientific and Technical Advisory Panel (STAP) of the Global Environmental Facility (GEF). [RATA]

34. Oregon Seismic Safety Policy Advisory Commission (OSSPAC) (2013). "The Oregon Resilience Plan: Reducing Risk and Improving Recovery for the Next Cascadia Earthquake and Tsunami." Salem, OR. [Oregon Resilience Plan]....

35. Peacock, W.G., Brody, S.D., Seitz, W.A., Merrell, W.J., Vedlitz, A., Zahran, S., Harriss, R.C. and Stickney, R. (2010). "Advancing resilience of coastal localities: Developing, implementing, and sustaining the use of coastal resilience indicators: A final report." Hazard Reduction and Recovery Center. 1-148. [Coastal Disaster Resilience Index (CDRI)] 
36. Pfefferbaum, R.L., Pfefferbaum, B., Van Horn, R.L., Klomp, R.W., Norris, F.H. and Reissman, D.B. (2013). "The communities advancing resilience toolkit (CART): An intervention to build community resilience to disasters." Journal of public health management and practice, 19(3), pp.250-258. [CART]

37. Prevention Institute (2004). "A Community Approach to Address Health Disparities: Toolkit for Health \& Resilience in Vulnerable Environments (THRIVE)." Washington, DC, Office of Minority Health, U.S. Department of Health and Human Services. [THRIVE]

38. Redman, C. L., J. Morgan Grove and L. H. Kuby (2004). "Integrating Social Science into the Long-Term Ecological Research (LTER) Network: Social Dimensions of Ecological Change and Ecological Dimensions of Social Change." Ecosystems 7(2): 161-171. [Long-Term Ecological Research Network [Long-Term Ecological Research Network]

39. Rose, A.Z. (2009). "A framework for analyzing the total economic impacts of terrorist attacks and natural disasters." Journal of Homeland Security and Emergency Management, 6(1). [CREATE]

40. San Francisco Planning and Urban Research Association (SPUR) (2009). "The Resilient City: Defining What San Francisco Needs from its Seismic Mitigation Policies." San Francisco, CA. [SPUR]......

41. Semper, T. T., D. L. Swann, R. Emmer, S. H. Sempier and M. Schneider (2010). "Coastal Community Resilience Index: A Community Self-Assessment." MASGP-08-014: National Oceanic and Atmospheric Administration (NOAA). [NOAA CRI] . 30

42. The International Federation of Red Cross and Red Crescent Societies (2014). "IFRC Framework for Community Resilience." Geneva, Switzerland, International Federation of Red Cross and Red Crescent Societies. [IFRC]

43. Twigg, J. (2007). "Characteristics of a Disaster-resilient Community: A Guidance Note, Version 1 (for field testing).” DFID Disaster Risk Reduction Interagency Coordination Group. [CDRC]

44. Twigg, J. (2009). "Characteristics of a Disaster-Resilient Community: A Guidance Note, Version 2." University College of London. [Disaster Resilient Community]

45. Tyler, S., M. Keller, D. Swanson, L. Bizikova, A. Hammill, A. N. Zamudio, M. Moench, A. Dixit, R. G. Flores, C. Heer, D. González, A. R. Sosa, A. M. Gough, J. L. Solórzano, C. Wilson, X. Hernandez and S. Bushe (2013). "IISD Report: Climate Resilience and Food Security: A Framework for Planning and Monitoring." Winnipeg, Manitoba, Canada, International Institute for Sustainable Development. [Climate Resilience and Food Security (IISD)] ...................................................... 33

46. Tyler, S., Nugraha, E., Nguyen, H.K., Van Nguyen, N., Sari, A.D., Thinpanga, P., Tran, T.T. and Verma, S.S. (2016). "Indicators of urban climate resilience: A contextual approach." Environmental science \& policy, 66. 420-426. [ACCCRN] .33

47. U.S. Department of Homeland Security (2016). "Mitigation Framework Leadership Group (MitFLG) Draft Concept Paper: Draft Interagency Concept for Community Resilience Indicators and National-Level Measures." Washington, DC, U.S. Department of Homeland Security. [MitFLG] .. 34 
48. U.S. Indian Ocean Tsunami Warning System Program (2007). "How Resilient Is Your Coastal Community? A Guide for Evaluating Coastal Community Resilience to Tsunamis and Other Hazards." U.S. Indian Ocean Tsunami Warning System Program supported by the United States Agency for International Development and partners, Bangkok, Thailand. 144. [Coastal Community Resilience to Tsunamis and Other Hazards].

49. UNDP Drylands Development Centre (2014). "Community Based Resilience Analysis (CoBRA) Conceptual Framework and Methodology." Commissioned by UNDP Drylands Development Centre, Under the Framework of: Humanitarian Aid and Civil Protection Department of the European Commission's Drought Risk Reduction Action Plan. [CoBRA] 36

50. United Nations Office for Disaster Risk Reduction (2017). "Disaster Resilience Scorecard for Cities, Detailed Level Assessment." United Nations Office for Disaster Risk Reduction (UNDRR) [UNISDR Scorecard].

51. United Nations and International Strategy for Disaster Reduction (ISDR) (2007). "Hyogo Framework for Action 2005-2015: Building the Resilience of Nations and Communities to Disasters." Extract from the final report of the World Conference on Disaster Reduction (A/CONF.206/6). Geneva, Switzerland, International Strategy for Disaster Reduction (ISDR). [Hyogo]......

52. United Nations Development Programme (UNDP) (2004). “A Global Report: Reducing Disaster Risk, a Challenge for Development.” New York, NY, United National Development Programme, Bureau for Crisis Prevention and Recovery. [UNDP DRI]...... .38

53. United Nations University - Institute for Environment and Human Security (UNU-EHS) (2014). "WorkRiskReport 2014." Bonn, Germany, United Nations University - Institute for Environment and Human Security (UNU-EHS). [WorldRiskIndex]

54. United States Agency for International Development (USAID) (2013). "THE RESILIENCE AGENDA: Measuring Resilience in USAID.” USAID. [Measuring Resilience in USAID] .............. 39

55. Vaitla, B., G. Tesfay, M. Rounseville and D. Maxwell (2012). "Resilience and Livelihoods Change in Tigray, Ethiopia." Somerville MA, Feinstein International Center, Tufts University. [Resilience and Livelihoods Change].....

56. Washington State Emergency Management Council: Seismic Safety Committee (2012). "Resilient Washington State: A Framework for Minimizing Loss and Improving Statewide Recovery after an Earthquake." Olympia, WA, Washington State Seismic Safety Committee. [Resilient Washington] 


\section{Introduction and Objectives}

The number of hazardous events, and the amount of damage caused by them, in the United States has been rising steadily over the last few decades (NOAA 2021). In parallel, there has been increasing interest in planning and policy approaches that enhance community resilience and reduce the impacts of hazardous events (Clavin et al. 2021). Communities interested in improving their resilience to hazards and other disruptions require decision-support and assessment tools to gather baseline data, evaluate program impacts or effectiveness, and monitor changes over time (e.g.: Clavin 2020). However, community resilience is a complex concept to measure owing to the fact that it emerges from the interdependencies of social, economic, natural, and physical systems. As the number of resilience assessment tools using different theoretical approaches and methods has grown (Beccari 2016; Cutter 2016; Sharifi 2016; Bakkensen 2017; Edgemon et al. 2019), there is a lack of consensus with respect to the theoretical approach taken, indicators used, data needs, and scale of application among resilience assessment methodologies and tools (Lavelle et al. 2015; Kwasinski et al. 2016; Kwasinski et al. 2017; Dillard 2018a). A review and summary of the frameworks supporting these tools provides a more holistic understanding of the approaches, indicators, and measures being used, and provides a basis for further analysis to identify patterns and gaps in current efforts.

As a part of ongoing efforts in the development of a methodology to measure community resilience, The National Institute of Standards and Technology (NIST) has constructed a Resilience Indicator Inventory (see: link) wherein 56 resilience frameworks and assessment methodologies were systematically summarized in a 2018 published dataset (Dillard 2018b). The Inventory produced a synthesized dataset comprising of the frameworks, their indicators, and associated measures (where present). This annotated bibliography, serving as a companion product to the Resilience Indicator Inventory, provides context on the 56 primary sources used. Namely, it summarizes the goals, intended audience, and development methodology of each framework, which are not provided in the Inventory, as well as a summary of main Inventory findings (see next section for further details). Collectively, this annotated bibliography, the Inventory, and other associated products and publications (see: link), will serve as a resource for practitioners and other researchers working in community resilience, and also facilitate the development of a validated and scientifically grounded assessment methodology at NIST.

The objectives of this annotated bibliography are:

- Collect and summarize previous work in community resilience measurement and assessment and identify similarities and differences in the goals, scope, and definitions of resilience in these approaches.

- Provide broad-scale summaries of each framework's approach and requirements as a resource for those seeking to conduct their own community resilience assessment for planning, or for researchers examining community resilience frameworks and measurement. 
- Inform the development of the NIST community resilience assessment methodology, as well as other ongoing and future efforts in resilience metrology. For example, informing literature reviews on common methods utilized within the field of community resilience assessment (see Section 4 for more details).

\section{Inventory Article Selection and Analysis Methods}

The goal of the Resilience Indicator Inventory (hereafter referred to as "the Inventory" (Dillard 2018b) was to gather, analyze, and document existing frameworks for the purposes of developing a community resilience measurement methodology. In addition, NIST researchers envision the Inventory as beneficial to academic researchers and practitioners, as well as other community stakeholders as they work to understand the many community resilience methods available. The Inventory, coupled with this summary of Inventory source contents, and other community resilience assessment products (see the NIST Community Resilience Group products page for more details: $\underline{\text { link}), ~ p r o v i d e s ~ a ~ r e s o u r c e ~ f o r ~ r e s e a r c h e r s ~ o r ~ c o m m u n i t i e s ~ t o ~ u s e ~ e x i s t i n g ~}$ frameworks for tailoring a methodology to assess their community's resilience. Such assessment may be beneficial for the purposes of securing grant funding, prioritizing investments, or for furthering community resilience research.

The Inventory comprises a sample of 56 frameworks and assessment methods selected as the initial data set, with the idea that future methodologies and frameworks could be added. These frameworks were identified and selected by subject matter experts in the areas of community resilience and indicator-based measurement. The frameworks cover multiple disciplinary perspectives (e.g., economics, urban planning, and engineering) and numerous focal areas (e.g., natural, physical, and/or social systems). Further, these frameworks operate at different spatial scales, may focus on different systems, and are at various stages of development and implementation (from those that are entirely conceptual to those that have already been applied). While this sample is not an exhaustive list of every resilience indicator or framework, it provides breadth of the approaches.

For each framework or methodology, a published source document (e.g., journal articles, gray literature, and guidance documents), was identified and all applicable indicators and associated measures were entered into a structured database using a consistent methodology. Specifically, frameworks were categorized based on their systems focus areas (e.g. buildings; economics; health; natural systems), and their spatial units of analysis used (e.g. households; census blocks; countries; ecosystems). In addition, the applicable hazard types of focus and if the framework had been applied before or was purely conceptual. The specific indicators and associated measures, where applicable, were then listed for each framework and these were further categorized individually. For more details on the categories and decision rules for the standardization of data entry, please see the data article which is also associated with the Inventory (see: link). 
The following annotations provide additional context for the Resilience Indicator Inventory. In some cases, documents were removed from their original online locations or updated since the Resilience Indicator Inventory was completed. In these cases, the closest and best available documents were used for the annotations. ${ }^{1}$ These instances will be noted in the annotations below.

In this review, each of the Inventory's 56 source documents was annotated using a standard format that summarizes:

1. The goals and scope of the framework or assessment method: namely the broad goals (e.g. anticipated end products or outcomes) of the framework or assessment tool, as well as it's intended audience or applications.

2. A summary of main findings from the Inventory analysis: namely the system focus areas, spatial units of analysis used, and total number of indicators and measures proposed. (Note that additional data provided in the Inventory such as hazard types of focus and if the framework had been applied or is purely conceptual was not included in this summary, but can be viewed in the Inventory: $\underline{\text { link). }}$.

3. How the framework or assessment method was developed or refined (i.e. qualitative and quantitative methods such as literature review, expert review, and/or case studies).

4. How the framework or assessment method defines resilience (if no explicit definition is provided, this section will read "None provided").

The following section (Section 3) provides annotations of the 56 selected frameworks, followed by a brief discussion of findings and potential applications of this and related NIST tools to future planning and research efforts (Section 4).

\footnotetext{
${ }^{1}$ Due to the time at which this document is being produced, some citations listed do not perfectly align with the citations provided in the Inventory. To aid in making linkages between the documents, Column $\mathrm{C}$ in the Indicator Inventory "Annotation Number" (in the "Frameworks Data" tab) provides the annotation number for each inventory item in line with the citation order presented here.
} 


\section{Annotated Bibliography of Resilience Frameworks and Assessment Tools}

The annotations in this document are presented in alphabetical citation order and can be quickly found in the online NIST Inventory of Community Resilience Indicators \& Assessment Frameworks (see: link) (Dillard 2018b) by searching for the "Short Name" which appears in brackets $[\ldots]$ at the end of each citation. In v.02 of the indicator inventory, annotation entries are further linked by "Annotation Number" (see column C in the "Frameworks Data" tab), which provides the annotation number for each inventory item in line with the citation order presented here.

1. ARUP International Development (2016). "City Resilience Index: Understanding and Measuring City Resilience." London, UK. [ARUP - city]

Goals \& Scope: The ARUP City Resilience Index is a question-based assessment tool designed to quantify a city's baseline levels of resilience, performance over time, and identify areas of strength and weakness, including the needs of vulnerable groups. It was designed primarily for use by city governments with access to administrative data but could also be used by nonprofit or community groups. The tool can be accessed via an online platform and provides a resilience profile for the community.

\section{Framework Summary:}

- Focal areas: buildings, infrastructure, economics, health, other social systems, and natural systems

- Unit of analysis: households and municipalities

- Total number of measures and indicators: 542

Development Process: Developed internationally via literature review and case studies in six geographically diverse cities; Cali, Colombia; Concepción, Chile; New Orleans, USA; Cape Town, South Africa; Surat, India; and Semarang, Indonesia. Goal areas and specific indicators were then refined to their final forms via peer review and were pilot tested in other cities.

Definition of resilience: "City resilience describes the capacity of cities to function, so that the people living and working in cities - particularly the poor and vulnerable - survive and thrive no matter what stresses or shocks they encounter." (Page 11). 
2. ARUP International Development and International Federation of Red Cross and Red Crescent Societies (2011). "Characteristics of a Safe and Resilient Community: Community Based Disaster Risk Reduction Study." Geneva, Switzerland, International Federation of Red Cross and Red Crescent Societies. [ARUP - International]

Goals \& Scope: This report identifies generalizable characteristics of safe and resilient communities, and documents the impacts of Red Cross-Red Crescent programs based on these characteristics. Specifically: the presence of knowledge and health, organization, connection, infrastructure and services, economic opportunities, and natural resource management within communities. These characteristics can be used for future program design and evaluation.

\section{Framework Summary:}

- Focal areas: buildings, infrastructure, economics, health, other social systems, and natural systems

- Unit of analysis: communities

- Total number of measures and indicators: 68

Development Process: The characteristics were developed by ARUP on behalf of the Community Based Disaster Risk Reduction programs, based on both literature review and findings from their Tsunami Recovery Programs. Specifically, the literature review resulted in a conceptual framework of 19 resilience characteristics. These were then field-tested through workshops in 30 communities in Sri Lanka, Indonesia, Thailand, and the Maldives. Through comparing themes and resilience factors emerging from the workshops with the original framework, six final resilience characteristic themes and 68 factors were identified.

Definition of resilience: "Hence community resilience is referred to as 'the capacity or ability of a community to anticipate, prepare for and respond to, and recover quickly from impacts of disaster' (Mayunga, 2008:2), or 'the ability of a system, community or society to resist, absorb, cope with and recover from the effects of hazards'(Pasteur, 2011:13)." (Page 22).

3. Bates, F. L. and W. G. Peacock (1992). "Measuring Disaster Impact on Household Living Conditions: The Domestic Assets Approach." International Journal of Mass Emergencies and Disasters 10: 133-160. [Domestic Assets Index]

Goals \& Scope: This article introduces the "domestic assets index" as an instrument for measuring baseline levels and change in household living conditions. The index is designed to assess disaster impacts on facilities and belongings that enable ordinary household functions (e.g. shelter, food, sleep, and sanitation). The authors recommend using the index in combination with measures of disaster damages to assess the reduction in living conditions and their rate of recovery. 


\section{Framework Summary:}

- Focal areas: infrastructure, economics, health, other social systems, and natural systems

- Unit of analysis: households

- Total number of measures and indicators: 18

Development Process: The index was based on a previous scale of household functional efficiency (Belcher, 1972) with alterations made for a focus on scoring the replacement costs of household elements. The index was then cross-tested for reliability and validity using interviews in 6 countries in the US, South America and Europe, ending with 10 focus areas of domestic function: shelter, food preservation, food preparation, sleeping, human waste disposal, bathing, clothes washing, dish and utensil washing, water, heating, and communications.

Definition of Resilience: None provided.

4. Belcher, J.C. (1972). "A cross-cultural household level-of-living scale." Rural Sociology, 37(2), p.208. [Level-of-Living Scale]

Goals \& Scope: This article proposes an adaptable level-of-living scale (i.e. standard of living; socioeconomic status), which uses a list of 14 household material items to score households and allow comparisons between societies or over time. These items are linked to certain household functions such as providing shelter (the construction of exterior walls, floor, and roof), water storage and transportation, and food storage and preparation.

\section{Framework Summary:}

- Focal areas: buildings, infrastructure, economics, health, and other social systems

- Unit of analysis: counties

- Total number of measures and indicators: 70

Development Process: In selecting the material items used for the scale, the author utilized survey data from households in Camden County, Georgia and considered the item's function and use as well as if it was owned. The scale was also modified for local contexts and tested in samples of households in Puerto Rico and the Dominican Republic.

Definition of Resilience: None provided. 
5. Bene, C., T. Frankenberger, M. Langworthy, M. Mueller and S. Martin (2016). "The Influence of Subjective and Psycho-social Factors on People's Resilience: Conceptual Framework and Empirical Evidence." Technical Report Series No. 2: Strengthening the Evidence Base for Resilience in the Horn of Africa, A joint International Livestock Research Institute (ILRI) and TANGO International publication. [Psycho-social Factor on People's Resilience]

Goals \& Scope: This article proposes a conceptual model that incorporates subjective, psychosocial factors (e.g. perceptions of susceptibility, control, and adaptability) in tandem with objective factors that influence resilience. The goal of this integration is to achieve a more holistic understanding of household resilience.

\section{Framework Summary:}

- Focal areas: infrastructure, economics, health, and other social systems

- Unit of analysis: households and communities

- Total number of measures and indicators: 25

Development Process: The conceptual model was developed based on the work of Béné, Frankenberger \& Nelson (2015) and Béné et al. (2016), which suggested that the outcomes of adverse events are affected by both the initial shock/stressor and the actions taken to counteract these shocks. The validity of the model and associated hypotheses was then supported in several case studies focused on fishing and rural communities in Africa and Asia.

Definition of resilience: "Subjective resilience relates to the assumption that people have a good understanding of the factors that enable them to manage shocks and adverse events. Household subjective resilience, therefore, relates to the self evaluation of individuals' or households' capacities and is strongly related to and influenced by the psycho-social factors mentioned above (e.g. self-confidence, risk aversion)." (Page 8).

6. Berkes, F. and C. S. Seixas (2005). "Building Resilience in Lagoon Social-Ecological Systems: A Local-level Perspective." Ecosystems 8: 967-974. [Lagoon SES]

Goals \& Scope: A qualitative study of resilience indicators in lagoon communities, focused at the local level and utilizing a social-ecological systems (SES) approach. The objective of this research was to identify linked SES factors that help to build resilience among lagoon communities. Findings are applicable to lagoon communities in semi-tropical developing countries.

\section{Framework Summary:}

- Focal areas: infrastructure, economics, other social systems, and natural systems

- Unit of analysis: ecosystem

- Total number of measures and indicators: 25 
Development Process: The resilience framework was initially developed qualitatively based on a multi-year study on the dynamics of social-ecological systems (Folke et al. 2003), and was then cross-referenced with five case studies in lagoon or estuarine social-ecological systems with intensive human uses in Brazil, India, Sri Lanka, and Turkey.

Definition of resilience: "Resilience is related to the magnitude of shock that a system can absorb and still remain within a given state, the self-organization capability of that system, and its capacity for learning and experimentation." (Page 967).

7. Brooks, N., S. Anderson, I. Burton, S. Fisher, N. Rai and I. Tellam (2013). “An Operational Framework for Tracking Adaptation and Measuring Development (TAMD)." IIED Climate Change Working Paper Series: Climate Change Working Paper No. 5. London, UK. [TAMD (Tracking Adaptation and Measuring Development)]

Goals \& Scope: The Tracking Adaptation and Measuring Development (TAMD) framework presents a conceptual method to assess climate adaptation interventions in developing countries. The assessment framework is flexible and can be applied at multiple spatial scales and timepoints. The authors suggest example indicators and measures which can be tailored to individual project needs. Results can then be used to assess project effectiveness or facilitate comparisons between projects.

\section{Framework Summary:}

- Focal areas: infrastructure, economics, other social systems, and natural systems

- Unit of analysis: communities

- $\quad$ Total number of measures and indicators: 45

Development Process: The framework builds on earlier efforts by The International Institute for Environment and Development and focuses on joint climate risk management and development performance, and the linkages between the two areas. Details on the selection and development of the framework and example indicators are not provided in this publication, although the framework itself and considerations for selecting indicators are discussed in detail.

Definition of resilience: None provided.

8. Canadian Centre for Community Renewal (2000). "The Community Resilience Manual: A Resource for Rural Recovery \& Renewal.” British Columbia, Canada, Canadian Centre for Community Renewal. [CR Manual]

Goals \& Scope: This guidance document is intended to assist rural communities in conducting cost-effective resilience and economic development planning, specifically to improve resilience to social and economic changes and shocks. It is a strategic planning process in which 
communities assess their current resilience on 23 characteristics and then set priorities to use available resources efficiently. The philosophy and approach of the guide is based on the tenants of Community Economic Development.

\section{Framework Summary:}

- Focal areas: economics, and other social systems

- Unit of analysis: rural communities

- Total number of measures and indicators: 61

Development Process: Focused on 23 characteristics of resilience, communities are encouraged to collect data and develop their own indicators to assess current community conditions and improvement over time. Worksheets are also provided to facilitate scoring on each of the 23 characteristics and to collect associated data, as a baseline measurement and to facilitate goal setting. Further details on development of the characteristics are not expanded upon in this document.

Definition of resilience: " $A$ resilient community is one that takes intentional action to enhance the personal and collective capacity of its citizens and institutions to respond to and influence the course of social and economic change." (Page 1-5).

9. Canterbury District Health Board (2016). "Canterbury Wellbeing Index 2016." Christchurch, New Zealand. [Canterbury Wellbeing Index]

Goals \& Scope: The Canterbury Wellbeing Index is a 17-point assessment method used to assess the social recovery of Christchurch over time, as well as compare it to other cities in New Zealand. It focuses on wellbeing indicators in the areas of knowledge, economics, housing, mental and physical health, safety, social connections, civil participation, and the population.

\section{Framework Summary:}

- Focal areas: buildings, infrastructure, economics, health, and other social systems

- Unit of analysis: other - international region

- Total number of measures and indicators: 120

Development Process: This effort was prompted by the widespread impacts of the 2010 and 2011 earthquakes and a desire to inform and track the progress of social recovery in the city of Christchurch. The index was developed via a meeting of agency representatives and literature review. The series of indicators utilizes administrative and survey data from several collaborating public agencies in New Zealand.

Definition of resilience: None provided. 
10. Community and Regional Resilience Institute (2011). "Community Resilience System Initiative (CRSI) Steering Committee final report: A roadmap to increased community resilience." Community and Regional Resilience Institute. [CARRI CRS]

Goals \& Scope: The Community Resilience System (CRS) is an online process that communities can use to assess current conditions and plan improvements to their resilience to numerous hazards. It was developed collaboratively by the Community \& Regional Resilience Institute (CARRI), which was tasked with investigating threats to American communities and the tools and resources needed to improve their resilience.

\section{Framework Summary:}

- Focal areas: buildings, infrastructure, economics, health, other social systems, and natural systems

- Unit of analysis: communities and counties

- Total number of measures and indicators: 241

Development Process: The CRS process was developed with input from over 150 representatives from community leadership, local, state, and federal government, research institutes, and the private sector in partnership with three communities in the southeastern US. The tool also utilizes existing concepts and resources from FEMA, the American Red Cross, The American Planning Association, and others.

Definition of resilience: "The CRSI [Community Resilience System Initiative] defines community resilience as the capability of a community to anticipate risk, limit impact, and recover rapidly through survival, adaptation, evolution, and growth in the face of turbulent change." (Page 12).

11. Cardona, O. (2005). "Indicators of disaster risk and risk management: Main technical report." Washington, DC. Inter-American Development Bank.[Disaster-Deficit Index (DDI)]

Goals \& Scope: The Disaster Deficit Index (DDI) is a disaster risk management metric and tool that models financial resilience. Specifically, it estimates national-level financial impacts due to a catastrophic event and compares this to the coping ability of a country in terms of resources available to recover. A higher index score indicates that anticipated losses outpace available recovery resources, resulting in national debt. This, and accompanying tools, can be used by national-level policy makers to identify sources of vulnerability and prioritize action.

\section{Framework Summary:}

- Focal areas: buildings, infrastructure, and economics

- Unit of analysis: countries

- Total number of measures and indicators: 7 
Development Process: The index is based on the conceptual framework proposed by Cardona et al. 2003. The set of four composite indicators and associated variables are based on extensive literature review and considering data availability related to risk factors that influence resilience and coping capacity. Index scores were calculated based on international data from 1980 and 2000, as well as expert estimates where existing measures were not available.

Definition of resilience: "Economic resilience... represents the possible internal and external funds available to government, in its role as a promoter of recovery and as owner of affected goods, at the moment of evaluation." (Page 5).

12. CGIAR Research Program on Water Land and Ecosystems (WLE) (2014). "Ecosystem Services and Resilience Framework." Colombo, Sri Lanka, CGIAR Research Program on Water, Land and Ecosystems, International Water Management Institute (IWMI). [CGIAR]

Goals \& Scope: A framework for improving the resilience of agriculture systems, focused on 23 ecosystem services such as providing food, water, and raw materials, regulating natural resources and the climate, and providing habitat and cultural services. Through promoting a focus on ecosystem services in resilience planning, the effort hopes to improve food and livelihood security and positively influence development.

\section{Framework Summary:}

- Focal areas: health, other social systems, and natural systems

- Unit of analysis: ecosystems

- $\quad$ Total number of measures and indicators: 76

Development Process: The framework and associated theory of change is based on previous research and theory in ecosystem services and resilience and proposes ways of integrating ecosystem services thinking into assessment, planning, implementation, and monitoring decision-making. These approaches are then illustrated with several case studies.

Definition of resilience: "Resilience, as we apply it here, means the ability of a socioecological system to undergo change and retain sufficient functionality to continue to support livelihoods through, for example, the sustained provision of ecosystem services, including the quantity, quality, access and utilization of food supply (Park et al. 2010)." (Page 4). 
13. Chandra, A., J. Acosta, S. Stern, L. Uscher-Pines, M. V. Williams, D. Yeung, J. Garnett and L. S. Meredith (2011). "Building Community Resilience to Disasters: A Way Forward to Enhance National Health Security." Santa Monica, CA, RAND Corporation with sponsorship by the U.S. Department of Health and Human Services. [BCRD]

Goals \& Scope: This report presents a definition of community resilience and roadmap for building it focused on improving health security. It presents a set of eight "levers" that enable faster recovery, and five "core components" to focus on in resilience planning activities. The results of the report are not a toolkit, but can be used as guidance by community leaders developing local resilience strategies, including government and nongovernment actors.

\section{Framework Summary:}

- Focal areas: economics, health, other social systems, and natural systems

- Unit of analysis: communities

- Total number of measures and indicators: 28

Development Process: The roadmap and suggested activities for improving health security was developed via thorough literature review and six stakeholder focus groups across the US, as well as meetings with subject matter experts (including researchers and federal and local health department representatives). The research was sponsored by the U.S. Department of Health and Human Services and carried out by the RAND Corporation.

Definition of resilience: "Community resilience entails the ongoing and developing capacity of the community to account for its vulnerabilities and develop capabilities that aid that community in (1) preventing, withstanding, and mitigating the stress of a health incident; (2) recovering in a way that restores the community to a state of self-sufficiency and at least the same level of health and social functioning after a health incident; and (3) using knowledge from a past response to strengthen the community's ability to withstand the next health incident." (Page xv).

14. Choptiany, J., B. Graub, S. Phillips, D. Colozza and J. Dixon (2015). "Self-Evaluation and Holistic Assessment of Climate Resilience of Farmers and Pastoralists (SHARP)." Rome, Italy, Food and Agriculture Organization of the United Nations (FAO). [SHARP]

Goals \& Scope: The Self-Evaluation and Holistic Assessment of Climate Resilience of Farmers and Pastoralists (SHARP) is an assessment tool focused on understanding and aiding in the climate resilience of rural agro-pastoralists. It utilizes a participatory self-assessment method for farmers and pastoralists focused on their current resources and climate resilience, which combined with a facilitated gap identification and climate data can be used to guide policy and intervention assistance at local to national scales. 


\section{Framework Summary:}

- Focal areas: economics, other social systems, and natural systems

- Unit of analysis: individuals, households, and communities

- Total number of measures and indicators: 145

Development Process: Development of the tool began with a literature review and qualitative review of existing assessment tools relevant to developing countries and rural agricultural systems. After discussion by experts at a workshop, previous tools and indicators were adapted to address future climate resilience more directly and focus at the household level, with a mixed qualitative - quantitative approach. The tool and its indicators also underwent several pilot tests in communities in Angola, Uganda, Senegal and Mali.

Definition of resilience: "For the purposes of this work we include notions of change or transformation as central to our definition of resilience, which we propose as: the ability of a system to recover, reorganise and evolve following external stresses and disturbances... We therefore suggest that there are benefits to conceptualizing resilience as both an outcome and inherent ability to adapt." (Page 26).

15. Constas, M. A. and C. B. Barrett (2013). "Principles of Resilience Measurement for Food Insecurity: Metrics, Mechanisms, and Implementation Issues." Expert Consultation on Resilience Measurement Related to Food Security. Rome, Italy, Food and Agricultural Organization and World Food Program. [Resilience Measurement for Food Insecurity]

Goals \& Scope: This paper provides a theory of resilience related to international development, poverty, and food security. Specifically, it identifies five measurement principles which help to inform the future creation of indicators for program evaluation and the empirical evaluation of resilience in the context of food security issues.

\section{Framework Summary:}

- Focal areas: infrastructure, economics, health, other social systems, and natural systems

- Unit of analysis: other - socioeconomic status

- Total number of measures and indicators: 14

Development Process: The measurement principles provided in this article were developed based on review of previous work and theory in areas such as ecological resilience and food security. The authors also suggest data collection and analysis options that can be used to improve the measurement of resilience and suggest a set of broad metric areas.

Definition of resilience: "Our conception resilience related to poverty and food security is as follows: Resilience represents the likelihood over time of a person, household or other unit being 
non-poor and food secure in the face of various stressors and in the wake of myriad shocks. If and only if that likelihood is and remains high, then the unit is resilient." (Page 2).

16. Cutter, S. L., K. D. Ash and C. T. Emrich (2014). "The Geographies of Community Disaster Resilience." Global Environmental Change 29: 65-77. [BRIC]

Goals \& Scope: This article describes the development and testing of an empirically based disaster resilience assessment metric called the Baseline Resilience Indicators for Communities (BRIC). The metric can be used by communities to quantify their inherent resilience as a score and provide guidance on where interventions may most improve resilience. It is intended to capture the multiple dimensions involved in disaster resilience while being easy to compute using publicly accessible US county-level data.

\section{Framework Summary:}

- Focal areas: buildings, infrastructure, economics, health, other social systems, and natural systems

- Unit of analysis: counties

- Total number of measures and indicators: 55

Development Process: The framework was conceived and refined via conceptual, theoretical, and empirical (data-driven) criteria, ending with a final set of 49 indicators. In addition to deductive methods, inductive methods for selecting and grouping indicators included principal components analyses and factor analysis. Data was obtained from US federal government data portals (including the US Census and American Community Survey), the Hazards and Vulnerability Research Institute, nonprofit groups' websites, and news outlets.

Definition of resilience: “...disaster resilience enhances the ability of a community to prepare and plan for, absorb, recover from, and more successfully adapt to actual or potential adverse events in a timely and efficient manner including the restoration and improvement of basic functions and structures." (Page 65).

17. Cutter, S. L., B. J. Boruff and W. L. Shirley (2003). "Social Vulnerability to Environmental Hazards (SoVI)." SOCIAL SCIENCE QUARTERLY - Southwestern Social Science Association 84(2): 242-261. [SoVi]

Goals \& Scope: The Social Vulnerability to Environmental Hazards Index (SoVI) consists of 11 factors selected from Census data which produce a score of a county's estimated social vulnerability to environmental hazards. Output from the index advances empirical understanding of social vulnerability, and can be used by local decision-makers to identify weaknesses and target resources or resilience interventions in their communities. 


\section{Framework Summary:}

- Focal areas: buildings, infrastructure, economics, other social systems, and natural systems

- Unit of analysis: counties

- Total number of measures and indicators: 70

Development Process: The index was developed with a data-driven approach, starting with over 250 variables sourced from county-level sociodemographic data from all US counties (year 1990). Following data cleaning, 42 variables were included in statistical analysis where they were reduced to 11 factors using principal components analysis. These 11 factors align well with current literature on social vulnerability and were combined in the additive model to produce the index summary score for each US county.

Definition of resilience: None provided.

18. DFID-funded International Climate Fund (ICF) (2014). "Methodology for Reporting Against KPI 4 - Number of People Whose Resilience Has Been Improved as a Result of Project Support.” [BRACED]

Goals \& Scope: This report document (which was withdrawn in March 2017) provides guidance on how communities can quantify project outcomes, targeted to recipients of the UK's Building Resilience and Adaptation to Climate Extremes and Disasters (BRACED) program. Specifically, the proposed process is intended to help recipients select indicators and calculate the number of individuals who have improved resilience as a result of project implementation. (Note that this methodology was updated and replaced with new guidance in 2019 - available at: link).

\section{Framework Summary:}

- Focal areas: infrastructure, economics, and other social systems

- Unit of analysis: other - project outcomes

- $\quad$ Total number of measures and indicators: 27

Development Process: Reporting grant recipients were encouraged to follow a process to calculate project outcomes where they: 1) identify the climate shocks and consequences they are looking to ameliorate, 2) articulate how project outputs were expected to improve resilience, and 3) identify specific impacts the project is expected to have, and 4) develop their own indicators for success based on those expected impacts. Further guidance is provided in the creation of effective resilience indicators, gathering needed data, and performing calculations.

Definition of resilience: "Here, resilience to climate shocks and stresses (that may be intensifying as a result of climate change) is considered to be a composite attribute possessed by each individual that represents their ability to anticipate, avoid, plan for, cope with, recover 
from and adapt to (climate related) shocks and stresses. Improved resilience means that an individual is better able to maintain or improve their well-being despite being exposed to shocks and stresses." (Page 4).

19. Dillard, M. K., T. L. Goedeke, S. Lovelace and A. Orthmeyer (2013). "Monitoring Wellbeing and Changing Environmental Conditions in Coastal Communities: Development of an Assessment Method." NOAA Technical Memorandum NOS NCCOS 174. Silver Spring, MD, NOAA National Centers for Coastal Ocean Science (NCCOS). [NOAA Community well-being]

Goals \& Scope: This report details the development of a framework and set of indicators using well-being as the central conceptual approach. It is designed to enable measurement of social and ecological interactions in coastal ecosystems, and to monitor responses to disruptions and interventions over time. It was originally developed to monitor changes in well-being in coastal communities related to the Deepwater Horizon disaster and responses to associated recovery programs over time.

\section{Framework Summary:}

- Focal areas: buildings, infrastructure, economics, health, other social systems, and natural systems

- Unit of analysis: counties and ecosystems

- Total number of measures and indicators: 64

Development Process: The framework and indicators were developed via a case study in the Gulf of Mexico, with a sample of 37 counties. First, a theoretical framework was developed via literature review, and indicators were identified and prioritized in a modified Delphi process in an expert workshop. Final indicators were then selected based on which had existing associated data and could be operationalized, as well as several theoretical considerations. Associated measures and composite indicators were then selected by considering theoretical and methodological factors, as well as through statistical testing using a compilation of existing secondary data from $2000-2011$.

Definition of Resilience: None provided. 
20. Elasha, B. O., N. G. Elhassan, H. Ahmed and S. Zakieldin (2005). "Sustainable livelihood approach for assessing community resilience to climate change: case studies from Sudan (AIACC Working Paper No. 17 August 2005).” Assessments of Impacts and Adaptations of Climate Change (AIACC). [AIACC Sustainable livelihood]

Goals \& Scope: This report describes the development of a sustainable livelihood-based conceptual framework for assessing climate resilience. Focused on livelihood assessment, the framework and associated indicators are focused on measuring the effectiveness of climate change resilience strategies on local livelihoods, mainly to droughts. After further development in collaboration with local stakeholders, specific indicators were used in pre- and postimplementation surveys to assess the impact of climate resilience strategies on local livelihoods in Sudan.

\section{Framework Summary:}

- Focal areas: buildings, economics, health, other social systems, and natural systems

- Unit of analysis: communities and countries

- Total number of measures and indicators: 74

Development Process: The conceptual framework was based on the UK Department of Foreign and International Development's (DFID) sustainable livelihood model, and initial indicators were developed by selecting previously used qualitative and quantitative measures that were relevant to a rural, drought-based context. The core set of indicators was then refined with community members at a case study site by discussing local conditions, goals, and concerns.

Definition of Resilience: None provided.

21. Federal Emergency Management Agency (FEMA) (2017, 3/27/2017). "Hazus." 4.0. 2017. from https://www.fema.gov/hazus. [HAZUS-MH]

Goals \& Scope: FEMA's Hazus tool allows planners and policy decision-makers to estimate the economic and social impacts from different hazards, utilizing an online, GIS-based model. The program includes models for hurricane (wind), flooding, and earthquake events, and is intended to aid in resilience decision-making at the local, state, and regional level through running different simulations. (For example, a local government could use the tool to compare the costs and benefits of mitigation strategies, given the expected losses if they are or are not applied).

\section{Framework Summary:}

- Focal areas: buildings, infrastructure, economics, health, and other social systems

- Unit of analysis: Census blocks, Census tracts, communities, counties, intrastate regions, states / territories, and interstate regions

- Total number of measures and indicators: 2051 
Development Process: Developed by the National Institute of Building Sciences (NIBS) for the Federal Emergency Management Agency (FEMA), the models produce several outputs including maps of the anticipated hazard, damage probabilities of buildings and essential facilities (such as physical damage, business losses, and relocation costs), as well as social and other estimated losses. There is both a basic analysis option utilizing data in the software, and an advanced analysis which requires more significant expertise and data input.

Definition of resilience: None provided.

22. Fisher, R.E., Bassett, G.W., Buehring, W.A., Collins, M.J., Dickinson, D.C., Eaton, L.K., Haffenden, R.A., Hussar, N.E., Klett, M.S., Lawlor, M.A. and Millier, D.J. (2010). "Constructing a resilience index for the enhanced critical infrastructure protection program (No. ANL/DIS-10-9).” Argonne National Lab (ANL), Argonne, IL, Decision and Information Sciences. [Resilience Index]

Goals \& Scope: This report details an assessment methodology developed by the Department of Homeland Security (DHS) focused on the resilience of critical infrastructure. The assessment methodology focuses on three main areas: robustness, resourcefulness, and recovery, and produces a Resilience Index (RI) score ranging from 1 - 100. The assessment can be used to support prioritized risk planning and disaster response, as well as enable comparisons between similar facilities within sectors or sub-sectors.

\section{Framework Summary:}

- Focal areas: buildings, infrastructure, economics, health, and other social systems

- Unit of analysis: buildings and organizations

- Total number of measures and indicators: 195

Development Process: Indices were developed to consider all components of critical infrastructure resilience, such as threats and consequences. In terms of process, data is initially collected by a DHS protective security advisor (PSA) at a site visit using a thorough assessment questionnaire. This data is then analyzed and scored by DHS personnel and subject matter experts using a decision analysis and ranking method to produce the resilience index score.

Definition of resilience: "NIAC [the National Infrastructure Advisory Council] defined resilience, in the context of CIKR [critical infrastructure and key resource], as the ability to reduce the magnitude and/or duration of disruptive events. The effectiveness of a resilient infrastructure or enterprise depends on its ability to anticipate, absorb, adapt to, and rapidly recover from a potentially disruptive event, whether naturally occurring or human caused (NIAC 2009)." (Page 5). 
23. Frankenberger, T., T. Spangler, S. Nelson and M. Langworthy (2012). "Enhancing Resilience to Food Security Shocks in Africa." TANGO International. [TANGO]

Goals \& Scope: This paper presents a conceptual framework and guidelines for assessing resilience, and the efficacy of resilience interventions, focused on communities within the Horn of Africa and the Sahel. The paper also suggests numerous strategies for achieving resilience in the areas of risk management, adaptive capacity, and governance. More broadly, utilization of the framework could inform prioritization of resilience programs and policies at multiple scales.

\section{Framework Summary:}

- Focal areas: infrastructure, economics, health, other social systems, and natural systems

- Unit of analysis: individuals, households, communities, and countries

- Total number of measures and indicators: 85

Development Process: The conceptual framework was developed by integrating livelihoods, risk reduction, and climate change approaches into a broad understanding of vulnerability. Guidelines of important factors and a discussion of measurement methods and considerations is also provided.

Definition of resilience: "The ability of countries, communities, and households to anticipate, adapt to, and/or recover from the effects of potentially hazardous occurrences (natural disasters, economic instability, conflict) in a manner that protects livelihoods, accelerates and sustains recovery, and supports economic and social development." (Page 1).

24. Hegney, D., H. Ross, P. Baker, C. Rogers-Clark, C. King, E. Buikstra, A. Watson-Luke, K. McLachlan and L. Stallard (2008). "Building Resilience in Rural Communities: Toolkit.” Toowoomba, Queensland, Australia, University of Queensland and University of Southern Queensland. [Rural Communities Toolkit]

Goals \& Scope: This toolkit is focused on enhancing rural community resilience based in 11 conceptual areas: social networks and support, positive outlooks, learning, early experiences, environment and lifestyles, infrastructure and support services, a sense of purpose, diverse and innovative economies, embracing differences, beliefs, and leadership. The toolkit is intended for use by program and community coordinators to guide rural wellbeing and resilience efforts.

\section{Framework Summary:}

- Focal areas: buildings, infrastructure, economics, health, other social systems, and natural systems

- Unit of analysis: individuals, organizations, and communities

- Total number of measures and indicators: 97 
Development Process: The toolkit's 11 resilience concepts were developed following literature review and interviews with a diverse set of residents in the rural community of Stanthorpe, Australia (including those in the commercial and service sectors, farmers, and youths). In these interviews, residents described their perceptions and drivers of individual wellness and community resilience in rural areas.

Definition of resilience: "Resilience refers to the capacity of an individual or community to cope with stress, overcome adversity or adapt positively to change. The ability to 'bounce back' from negative experiences may reflect the innate qualities of individuals or be the result of learning and experience." (Page 3).

25. Institute of Governmental Studies: The University of California Berkeley (2017). "Resilience Capacity Index" (RCI). Building Resilient Regions. Retrieved 8/7/2017, from http://brr.berkeley.edu/rci/. [RCI]

Goals \& Scope: The Resilience Capacity Index (RCI) is a single score used to estimate a region's capacity to be resilient to future stressors, based on the status of 12 factors in three main areas: economic capacity, socio-demographic capacity, and community connectivity capital. As the scoring system is standardized, it can be used to quickly compare relative resilience between metropolitan regions.

\section{Framework Summary:}

- Focal areas: infrastructure, economics, and other social systems

- Unit of analysis: metropolitan areas, and intrastate regions

- Total number of measures and indicators: 17

Development Process: The RCI was developed by a research team based on literature review and the selection of indicators with readily measured and widely available municipal data. In terms of calculation, scores on the 12 factors have equal weight, and are reported as z-scores in terms of how much a region's performance deviates from an average score.

Definition of resilience: "Regional resilience refers to the ability of a place to recover from a stress, either an acute blow, as in the case of an earthquake or major plant closing, or a chronic strain, as may occur with longstanding economic decline or unremitting rapid population growth." (Page 3)

26. Inter-Agency Standing Committee (2005). "IASC In-Country Team Self-Assessment Tool for Natural Disaster Response Preparedness.” [IASC-NDRP]

Goals \& Scope: The Inter-Agency Standing Committee's self-assessment tool is intended for use by in-country teams to assess their current levels of disaster preparedness and identify areas 
to prioritize improvement. The tool takes the form of a simple checklist of 10 preparedness areas, with selected tools and resources for learning more about each. The preparedness areas include topics such as national capacity, hazard identification, vulnerability assessment, and human resource capacity.

\section{Framework Summary:}

- Focal areas: infrastructure, economics, health, and other social systems

- Unit of analysis: countries

- Total number of measures and indicators: 71

Development Process: The assessment tool was developed by the Inter-Agency Standing Committee, the humanitarian coordination forum created by the United Nations (UN) General Assembly. Details on the development of the tool and its focus areas are not provided in this document.

Definition of resilience: None provided.

27. Keating, A., K. Campbell, R. Mechler, E. Michel-Kerjan, J. Mochizuki, H. Kunreuther, J. Bayer, S. Hanger, I. McCallum, L. See, K. Willigies, A. Atreya, W. Botzen, B. Collier, J. Czajkowski, S. Hochrainer and C. Egan (2014). "Operationalizing Resilience against Natural Disaster Risk: Opportunities, Barriers, and a Way Forward.” Zurich, Switzerland, Zurich Flood Resilience Alliance. [Zurich Flood Resilience Alliance]

Goals \& Scope: The Flood Resilience Measurement for Communities (FRMC) framework and tool is intended to identify current risks and performance measures specific to flooding, as well as identify and monitor solutions for improving resilience. Focused at the community level, it utilizes a systems-based perspective measuring social, human, physical, financial, and natural assets.

\section{Framework Summary:}

- Focal areas: buildings, infrastructure, other social systems, and natural systems

- Unit of analysis: not provided

- Total number of measures and indicators: 11

Development Process: The framework was developed by the Zurich Insurance Group's flood resilience program and its research partners, using a basis in the five capitals $(5 \mathrm{C})$ model from the UK's Department for International Development and the four properties of a resilient system (4R). In this white paper, a review of previous indicators and measurement challenges is also provided, although no toolset or measurement process. 
Definition of resilience: "Disaster resilience is the ability of a system, community, or society to pursue its social, ecological, and economic development and growth objectives, while managing its disaster risk over time in a mutually reinforcing way." (Page 8).

28. Mayunga, J. S. (2007). "Understanding and Applying the Concept of Community Disaster Resilience: A capital-based approach." Summer academy for social vulnerability and resilience building, 1(1), 1-16. [Capital-Based CDR]

Goals \& Scope: This article proposes a theoretical framework for measuring community disaster resilience using a capitals-based approach, which focuses on components needed for the development and maintenance of a sustainable economic system (namely, social, economic, human, physical, and natural capitals). A thorough exploration of theoretical and statistical methods possible to develop specific indicators is also included.

\section{Framework Summary:}

- Focal areas: buildings, economics, other social systems, and natural systems

- Unit of analysis: communities

- Total number of measures and indicators: 21

Development Process: The framework was developed by first exploring how the concept of resilience has been discussed and defined in previous work, followed by a review of current frameworks and indicators. As potential next steps, the theoretical and statistical methods that could be used to advance and implement the framework are then discussed, such as normalizing scores, assigning weights based on theoretical considerations, and statistical methods such as confirmatory factor analysis.

Definition of Resilience: None provided.

29. Miles, S. B. and S. E. Chang (2011). "ResilUS: A Community Based Disaster Resilience Model." Cartography and Geographic Information Science 38(1): 5-21. [ResilUS]

Goals \& Scope: This article details the development of the model ResilUS, which simulates hazard event damages to the built environment, economic systems, and to human health, and the recovery of critical services over time at several hierarchical scales. At each scale, it is possible to alter household, economic, or political variables in the model to see the outcomes of decisions in experimental, "what if" scenarios. Due to several limitations it is recommended by the authors that the model be used primarily for educational, training, and public awareness purposes and not as a decision support tool. 


\section{Framework Summary:}

- Focal areas: buildings, infrastructure, economics, health, other social systems, and natural systems

- Unit of analysis: households, buildings, organizations, and communities

- Total number of measures and indicators: 45

Development Process: The model and its parameters were developed based on literature review and is focused on measurable aspects of community critical services and community capital. Data from the 1994 Northridge earthquake event was also used to calibrate the output variables. The model itself was developed in and is operated through MATLAB, and uses fragility curves to model losses and Markov chains to model recovery over time.

Definition of resilience: " $A$ resilient community is one that does not experience serious degradation in critical services when a hazard occurs and, in the event of degradation or failure, recovers to a similar or better level of service in a reasonable amount of time." (Page 36).

30. Miller, K. K., A. Johnson and B. Dabson (2016). "WORKING PAPER IPP/071: Measuring Resilience and Vulnerability in U.S. Counties.” University of Missouri Institute of Public Policy: Harry S Truman School of Public Affairs. [MRV]

Goals \& Scope: This working paper describes the creation of county-level indices to identify levels of resilience and vulnerability focused on 4 main dimensions of resilience and vulnerability: social, infrastructure, economic and environmental. The long-term goal of the effort is to provide tools for resilience plan preparation.

\section{Framework Summary:}

- Focal areas: infrastructure, economics, health, other social systems, and natural systems

- Unit of analysis: counties

- Total number of measures and indicators: 49

Development Process: Variables were identified through literature review, and existing countylevel data was then used to proxy for those variables (for example, $\%$ residency of longer than 1 year in the county was used for the variable "place attachment"). Conceptually, variables where higher values correspond to positive outcomes were included in the "resilience" index, while those where higher values corresponded to a negative outcome were included in the "vulnerability" index.

Definition of Resilience: None provided. 
31. National Preparedness Training Center - University of Hawaii (2011). "Coastal Community Resilience: Building Resilience from the Inside Out. (CCR)." FEMA, US Department of Homeland Security National Training and Education Division: 317-333. [CCR]

Goals \& Scope: The Coastal Community Resilience (CCR) Framework and training is designed to improve awareness of coastal hazards (including possible economic, social, and environmental impacts) and methods to prepare and recover from hazard events among decision-makers. Training activities include assessing current resources and identifying best practices for improving community resilience and response to future events.

\section{Framework Summary:}

- Focal areas: buildings, infrastructure, economics, health, other social systems, and natural systems

- Unit of analysis: communities

- Total number of measures and indicators: 85

Development Process: Details on development of the framework are not provided in this document.

Definition of resilience: Several definitions are provided, including: “...the official DHS [Department of Homeland Security] definition of resilience "is the ability of systems, infrastructures, government, business, and citizenry to resist, absorb, and recover from or adapt to an adverse occurrence that may cause harm, destruction, or loss of national significance" (HSAI, 2009; DHS, 2008)." (Page 28).

32. Norris, F. H., S. P. Stevens, B. Pfefferbaum, K. F. Wyche and R. L. Pfefferbaum (2007). "Community Resilience as a Metaphor, Theory, Set of Capacities, and Strategy for Disaster Readiness." American Journal of Community Psychology 41: 127-150. [Community Resilience and Disaster Readiness]

Goals \& Scope: This article presents a theory and model of community resilience and disaster readiness that incorporates concepts such as stressors, adaptation, population wellness, and resource dynamics. In it, community resilience emerges from a community's interconnected capacity for economic development, social capital, information and communication, and community competence.

\section{Framework Summary:}

- Focal areas: infrastructure, economics, health, and other social systems

- Unit of analysis: communities

- Total number of measures and indicators: 23 
Development Process: The model of community resilience was developed by combining previous disaster research with concepts from psychology, sociology, geography, anthropology, public health, ecology, technology, and communication. Discussion of resilience definitions and it's multiple applications (e.g. as a metaphor, process, or outcome, etc.), and for related complex concepts such as wellness, is also provided.

Definition of resilience: "Resilience: A process linking a set of adaptive capacities to a positive trajectory of functioning and adaptation after a disturbance." (Page 6; Table 2).

33. O'Connell, D., Walker, B., Abel, N., Grigg, N. (2015). “The Resilience, Adaptation and Transformation Assessment Framework: From Theory to Application." Commissioned by the Scientific and Technical Advisory Panel (STAP) of the Global Environmental Facility (GEF). [RATA]

Goals \& Scope: The Resilience, Adaptation and Transformation Assessment Framework and assessment process is focused on measuring and improving the resilience, climate adaptation, and sustainability of agroecosystems. The process assists in needs identification and project monitoring in line with objectives from the Rio Convention, and can be applied from household to sub-national scales. The assessment's indicators utilize existing data and provide a flexible, iterative, and participatory process which can vary in terms of analytical complexity.

\section{Framework Summary:}

- Focal areas: infrastructure, economics, health, other social systems, and natural systems

- Unit of analysis: households

- Total number of measures and indicators: 35

Development Process: The framework and its indicators were based on a thorough review and consideration of existing frameworks, theory, and literature on resilience assessment. A draft version was reviewed in a 2014 workshop with 50 experts from research and international organizations and tested in two case studies in Thailand and Niger. The resulting procedure follows a process of goal-setting, describing current and future systems, threats, and needs, and identifying possible interventions to improve resilience.

Definition of resilience: "The ability of a system to maintain high-level objectives (e.g. sustainability, rural livelihoods, ecosystem services) in the face of unknown changes or disturbance." (Page 6). 
34. Oregon Seismic Safety Policy Advisory Commission (OSSPAC) (2013). "The Oregon Resilience Plan: Reducing Risk and Improving Recovery for the Next Cascadia Earthquake and Tsunami." Salem, OR. [Oregon Resilience Plan]

Goals \& Scope: This document provides earthquake resilience planning guidance for the state of Oregon, with suggested policy options, incentives, and investments for improving earthquake recovery in communities. Analysis and recommendations are focused in eight sectors: business and workforces, coastal communities, critical and essential buildings, transportation systems, energy infrastructure, communication systems, and water and wastewater systems.

\section{Framework Summary:}

- Focal areas: buildings, infrastructure, economics, and health systems

- Unit of analysis: intrastate region

- Total number of measures and indicators: 740

Development Process: To begin their analysis, a task group reviewed current scientific research to develop a detailed scenario of a major earthquake and tsunami. This scenario was then used by eight working groups (made up of over 100 government and academic experts, and members of the public), to estimate impacts and performance gaps in the above-mentioned sectors. The groups then defined performance target goals for recovery time in each sector, and recommended changes to policy and practice to help reach those goals.

Definition of resilience: "Higher resilience requires minimal reductions in critical lifeline services after a disaster, speedy recovery of those services, and an overall improved service level as a result of rebuilding damaged systems and implementing better systems." (Page xv).

35. Peacock, W.G., Brody, S.D., Seitz, W.A., Merrell, W.J., Vedlitz, A., Zahran, S., Harriss, R.C. and Stickney, R. (2010). "Advancing resilience of coastal localities: Developing, implementing, and sustaining the use of coastal resilience indicators: A final report." Hazard Reduction and Recovery Center. 1-148. [Coastal Disaster Resilience Index (CDRI)]

Goals \& Scope: This report describes the development of a Community Disaster Resilience Framework and related community resilience indicators (CRIs) focused on coastal communities along the Gulf Coast. The goal of the project is to produce a both theoretically and empirically sound measure of community resilience to disasters, using regional and county-level data.

\section{Framework Summary:}

- Focal areas: buildings, infrastructure, economics, health, and other social systems

- Unit of analysis: counties

- Total number of measures and indicators: 97 
Development Process: The research team first developed a conceptual framework based on an exploration of resilience in various fields and three sustainability and resilience-focused frameworks. This effort was followed by the empirical development and refinement of measures to create a set of indicators, which included creating a systematic process for selecting indicators, standardizing them, and determining weights, followed by thorough reliability and validity testing (including content, construct, and predictive validity).

Definition of Resilience: None provided.

36. Pfefferbaum, R.L., Pfefferbaum, B., Van Horn, R.L., Klomp, R.W., Norris, F.H. and Reissman, D.B. (2013). “The communities advancing resilience toolkit (CART): An intervention to build community resilience to disasters." Journal of public health management and practice, 19(3), pp.250-258. [CART]

Goals \& Scope: The Communities Advancing Resilience Toolkit (CART) is a participatory planning process where stakeholders can assess community issues, obtain feedback, and strategize actions to improve resilience. Intended for use by community planners and organizations, the process is focused on four domains: connection and caring, resources, transformative potential, and disaster management. The toolkit includes products such as a community resilience field survey, a data collection framework, and a capacity and vulnerability assessment. (Note: this entry was created using the above 2013 Journal article; the Inventory entry was based on a 2011 version of the document. See Inventory "references" tab for details).

\section{Framework Summary:}

- Focal areas: buildings, infrastructure, economics, health, and other social systems

- Unit of analysis: communities

- Total number of measures and indicators: 157

Development Process: The toolkit was developed by the Terrorism and Disaster Center of the National Child Traumatic Stress Network, in partnership with researchers at the University of Oklahoma. The domains of focus are based in theory from social psychology (community capacity and competence) and public health literatures.

Definition of resilience: "Community resilience entails the ability of community members to take deliberate, purposeful, and collective action to alleviate the detrimental effects of adverse events." (Page 251). 
37. Prevention Institute (2004). "A Community Approach to Address Health Disparities: Toolkit for Health \& Resilience in Vulnerable Environments (THRIVE)." Washington, DC, Office of Minority Health, U.S. Department of Health and Human Services. [THRIVE]

Goals \& Scope: The Toolkit for Health and Resilience in Vulnerable Environments (THRIVE) is a framework and toolkit focused on identifying health and safety disparities and improving health equity within communities. Its assessment worksheet relies on a questionnaire and qualitative scoring system among socio-cultural factors (people), physical environment (place), and the economic environment (opportunities) to assess current conditions and identify priorities for change. Related resources for outreach, goal identification, and planning are also provided.

\section{Framework Summary:}

- Focal areas: buildings, infrastructure, economics, health, other social systems, and natural systems

- Unit of analysis: communities

- Total number of measures and indicators: 159

Development Process: The framework and associated tools utilizes 12 determinants of health and safety, grouped into three main areas: people, place, and opportunities. The factors were developed via literature review focused on health outcomes and their relationship to environmental factors, and through discussion by an expert panel. The toolkit has also been pilot tested in rural, urban, and suburban communities.

Definition of resilience: None provided.

38. Redman, C. L., J. Morgan Grove and L. H. Kuby (2004). "Integrating Social Science into the Long-Term Ecological Research (LTER) Network: Social Dimensions of Ecological Change and Ecological Dimensions of Social Change." Ecosystems 7(2): 161-171. [Long-Term Ecological Research Network [Long-Term Ecological Research Network]

Goals \& Scope: This article provides a broad framework for integrating social sciences at multiple levels into the study of long-term ecological change. The authors advocate for eliminating distinctions between human and natural systems in these contexts and to instead focus on complex Social-Ecological Systems (SESs). They also suggest using multiple temporal and spatial scales and diverse tools to model interactions between human and natural systems.

\section{Framework Summary:}

- Focal areas: economics, other social systems, and natural systems

- Unit of analysis: ecosystem, and other - general, multiple social scales

- Total number of measures and indicators: 20 
Development Process: The suggestions outlined in this paper resulted from a series of meetings beginning in 1998 of the Long-Term Ecological Research (LTER) National Science Foundation program. The concepts discussed are at a high level, and do not result in specific indicators and measures.

Definition of Resilience: None provided.

39. Rose, A.Z. (2009). "A framework for analyzing the total economic impacts of terrorist attacks and natural disasters." Journal of Homeland Security and Emergency Management, 6(1). [CREATE]

Goals \& Scope: This article provides a comprehensive framework for assessing economic losses from disaster events, considering direct economic impacts as well as the newer concept of resilience (in terms functional economic recovery), and behavioral and system linkages and indirect effects. The framework attempts to provide the major elements which should be included by decision-makers in loss estimation for disasters and cost-benefit analysis of policies. (Note: this entry was created using the above 2009 Journal article; the Inventory entry was based on a 2009 CARRI report version of the document. See Inventory "references" tab for details).

\section{Framework Summary:}

- Focal areas: buildings, infrastructure, economics, health, other social systems, and natural systems

- Unit of analysis: households, organizations, and communities

- Total number of measures and indicators: 124

Development Process: The framework incorporates several important concepts from loss estimation, including stocks and flows, the time duration of losses, and direct versus indirect impacts. It also considers behavioral and systems linkages which could result in cascading impacts, such as public fear or interrelated system failures.

Definition of resilience: "I define static economic resilience as the ability of an entity or system to maintain function (e.g., continue producing) when shocked (see also Rose, 2004b; 2007)... A more general definition that incorporates dynamic considerations is the speed at which an entity or system recovers from a severe shock to achieve a desired state." (Page 5).

40. San Francisco Planning and Urban Research Association (SPUR) (2009). "The Resilient City: Defining What San Francisco Needs from its Seismic Mitigation Policies." San Francisco, CA. [SPUR]

Goals \& Scope: This report establishes priorities and target recovery timelines for different classes of structures in San Francisco related to earthquake events. Recovery goals are focused 
both on prioritizing human safety and shortening response and recovery periods and are intended to inform city engineering standards and building codes.

\section{Framework Summary:}

- Focal areas: buildings, infrastructure, economics, health, and other social systems

- Unit of analysis: metropolitan area

- $\quad$ Total number of measures and indicators: 35

Development Process: Anticipated impacts and recovery targets were developed based on a large earthquake scenario also used for the city's Community Action Plan for Seismic Safety. Target recovery times are grouped into different priority systems including critical response facilities (e.g. hospitals and fire stations), residential housing and infrastructure (e.g. schools, retail services, and roads), and other locations (e.g. office workplaces).

Definition of resilience: "Resilient communities have an ability to govern after a disaster has struck. These communities adhere to building standards that allow the power, water, and communication networks to begin operating again shortly after a disaster and that allow people to stay in their homes, travel to where they need to be, and resume a fairly normal living routine within weeks." (Page 4).

41. Semper, T. T., D. L. Swann, R. Emmer, S. H. Sempier and M. Schneider (2010). "Coastal Community Resilience Index: A Community Self-Assessment.” MASGP-08-014: National Oceanic and Atmospheric Administration (NOAA). [NOAA CRI]

Goals \& Scope: The Coastal Community Resilience Index is a self-assessment tool designed to provide a quick and inexpensive estimate of post-disaster community recovery. Using scenarios of a "bad storm" and "future storm" as benchmarks, the tool can be completed by local-level officials, engineers, and planners using existing data to identify gaps in preparation. Completing the tool activity results in a low-medium-high resilience index score in different categories.

\section{Framework Summary:}

- Focal areas: buildings, infrastructure, economics, health, other social systems, and natural systems

- Unit of analysis: communities

- Total number of measures and indicators: 92

Development Process: Details on development of the assessment tool are not specified in this document.

Definition of resilience: "DISASTER RESILIENCE is the capacity of a community exposed to hazards to adapt, by resisting or changing, in order to reach and maintain an acceptable level of 
functioning and structure. RESILIENCE is determined by the degree to which the community is capable of organizing itself to increase its capacity for learning from past disasters." (Page 1).

42. The International Federation of Red Cross and Red Crescent Societies (2014). "IFRC Framework for Community Resilience." Geneva, Switzerland, International Federation of Red Cross and Red Crescent Societies. [IFRC]

Goals \& Scope: The IFRC Framework for Community Resilience is designed to unite and assess the numerous international efforts undertaken by the International Federation of Red Cross Societies. While focused at the community level, the framework conceptualizes resilience at multiple levels, from the individual and household level to national governments and whole geographic regions. Tools are also available to guide the selection of indicators based on common goals.

\section{Framework Summary:}

- Focal areas: buildings, infrastructure, economics, health, other social systems, and natural systems

- Unit of analysis: communities

- Total number of measures and indicators: 87

Development Process: Since it was first developed in 2008, the framework has been refined with input from numerous sources. This includes workshops with representatives from over 50 national societies, private-sector partners, and external organizations. Details on the initial development of the framework are not provided in this document.

Definition of resilience: "The IFRC [International Federation of Red Cross Societies] defines resilience as: the ability of individuals, communities, organizations or countries exposed to disasters, crises and underlying vulnerabilities to anticipate, prepare for, reduce the impact of, cope with and recover from the effects of shocks and stresses without compromising their longterm prospects." (Page 6).

43. Twigg, J. (2007). "Characteristics of a Disaster-resilient Community: A Guidance Note, Version 1 (for field testing).” DFID Disaster Risk Reduction Interagency Coordination Group. [CDRC]

Goals \& Scope: This report describes a framework designed to assist communities or governments in conducting resilience, climate adaptation, or disaster risk reduction planning by utilizing a series of resilience characteristics. These characteristics serve as a template from which communities can create goals, plan actions, and select success indicators tailored to their needs. Intended for use by governments or civil organizations at a community level. 


\section{Framework Summary:}

- Focal areas: buildings, infrastructure, economics, health, other social systems, and natural systems

- Unit of analysis: communities

- Total number of measures and indicators: 354

Development Process: The framework takes the form of a series of tables detailing resilience characteristics in the areas of governance, risk assessment, knowledge and education, risk management and vulnerability reduction, and disaster preparedness and response. This first edition framework was commissioned by a group of six international aid agencies involved in disaster risk reduction (DRR) initiatives in support of the Hyogo Framework for Action.

Definition of resilience: “...system or community resilience can be understood as: capacity to absorb stress or destructive forces through resistance or adaptation; capacity to manage, or maintain certain basic functions and structures, during disastrous events; capacity to recover or 'bounce back' after an event." (Page 6).

44. Twigg, J. (2009). "Characteristics of a Disaster-Resilient Community: A Guidance Note, Version 2." University College of London. [Disaster Resilient Community]

Goals \& Scope: This report describes a framework and engagement process designed to assist communities or governments in conducting resilience, climate adaptation, or disaster risk reduction planning by utilizing a series resilience characteristics. This effort is part of continued development of the 2007 Characteristics of a Disaster-resilient Community, which was fieldtested by multiple agencies and refined into this second (2009) edition. Intended for use by governments or civil organizations at a community level.

\section{Framework Summary:}

- Focal areas: buildings, infrastructure, economics, health, other social systems, natural systems, and also other systems

- Unit of analysis: individuals, households, buildings, organizations, and communities

- Total number of measures and indicators: 355

Development Process: This framework was based on the previous version published in 2007. The revised series of characteristics and engagement process was created following input from numerous field studies in countries including Bangladesh and Nepal.

Definition of resilience: “...system or community resilience can be understood as the capacity to: anticipate, minimize and absorb potential stresses or destructive forces through adaptation or resistance, manage or maintain certain basic functions and structures during disastrous events, recover or 'bounce back' after an event." (Page 8). 
45. Tyler, S., M. Keller, D. Swanson, L. Bizikova, A. Hammill, A. N. Zamudio, M. Moench, A. Dixit, R. G. Flores, C. Heer, D. González, A. R. Sosa, A. M. Gough, J. L. Solórzano, C. Wilson, X. Hernandez and S. Bushe (2013). "IISD Report: Climate Resilience and Food Security: A Framework for Planning and Monitoring.” Winnipeg, Manitoba, Canada, International Institute for Sustainable Development. [Climate Resilience and Food Security (IISD)]

Goals \& Scope: This report provides a conceptual framework and simple guidance tool which highlights key indicators of community and food system resilience at various spatial scales. The purpose of the tool is to inform policy related to climate change and disaster impacts on food production, transport, and access. Indicators are not quantified but serve as a flexible, visual guide of concepts to consider at various levels of planning, based on local goals.

\section{Framework Summary:}

- Focal areas: infrastructure, health, other social systems, natural systems, and other learning from experience and organizational support

- Unit of analysis: households, communities, countries, and ecosystems

- Total number of measures and indicators: 43

Development Process: The framework was developed through a review of existing food systems and climate resilience frameworks. It was then transformed into two conceptual graphics which summarize key factors in food system security and climate-related resilience at various spatial scales. Indicators were also field-tested through participatory processes in Guatemala, Honduras, and Nicaragua.

Definition of resilience: "Climate-resilient food systems are robust in the face of climate shocks, adapting and re-organizing to respond to stresses, and recovering quickly from extreme events." (Page 6).

46. Tyler, S., Nugraha, E., Nguyen, H.K., Van Nguyen, N., Sari, A.D., Thinpanga, P., Tran, T.T. and Verma, S.S. (2016). "Indicators of urban climate resilience: A contextual approach.” Environmental science \& policy, 66. 420-426. [ACCCRN]

Goals \& Scope: This article proposes a planning approach integrating expert-driven and locallydriven approaches to developing climate resilience indicators. By combining an overarching resilience framework with the identification of local priorities and indicators, the process results in locally relevant indicators while also fostering a shared understanding of city resilience among local stakeholder groups. Results from case studies suggest that resilience indicators can be effectively developed locally, even with limited resources and experience. (Note: this entry was created using the above 2016 Journal article; the Inventory entry was based on a 2014 Institute 
for Social and Environmental Transition working paper. See the Inventory "references" tab for details).

\section{Framework Summary:}

- Focal areas: buildings, infrastructure, economics, health, and other social systems

- Unit of analysis: households, and municipalities

- Total number of measures and indicators: 166

Development Process: Using eight cities in the Asian Cities Climate Change Resilience Network, unique resilience indicators were developed with input from technical experts and stakeholders as part of a local collaborative process. Each city group worked from a basis in The Institute for Social and Environmental Transitions (ISET) conceptual framework for urban climate resilience, from which they identified priority issues and developed resilience indicators based on local data availability.

Definition of resilience: "Within the urban climate resilience framework applied in this study (Tyler and Moench, 2012), building resilience means: strengthening infrastructure and ecosystems to reduce their fragility in the face of climate impacts and to reduce the risk of cascading failures; building the capacities of social agents to anticipate and develop adaptive responses, and to access and maintain supportive urban systems; and addressing the institutional factors that constrain effective responses to system fragility or undermine the ability of agents to take action." (Page 421).

47. U.S. Department of Homeland Security (2016). "Mitigation Framework Leadership Group (MitFLG) Draft Concept Paper: Draft Interagency Concept for Community Resilience Indicators and National-Level Measures.” Washington, DC, U.S. Department of Homeland Security. [MitFLG]

Goals \& Scope: The Mitigation Framework Leadership Group (MitFLG) provides a framework and associated indicators for assessing community resilience, with proposed measures that use existing Federal data. Based on an inter-agency collaboration, the approach is designed to work with existing state and national-level reporting requirements and help to align goals and establish common use of terms across agency efforts.

\section{Framework Summary:}

- Focal areas: buildings, infrastructure, economics, health, other social systems, and natural systems

- Unit of analysis: individuals, households, buildings, communities, municipalities, counties, and states

- Total number of measures and indicators: 42 
Development Process: The framework was developed through an interagency partnership called the Mitigation Framework Leadership Group (MitFLG), which consists of several US Federal agencies including FEMA and NOAA, and state agency representatives. Indicators were selected from key findings via literature review of academic, government, business, and nonprofit publications. Associated measures were proposed based on Federal-level data fully developed and approved for use in the effort.

Definition of resilience: "Community Resilience, as defined by Presidential Policy Directive (PPD) 8-National Preparedness and the NPG, is the ability of a community to adapt to changing conditions, withstand disruption, and rapidly recover from emergencies." (Page 3 ).

48. U.S. Indian Ocean Tsunami Warning System Program (2007). "How Resilient Is Your Coastal Community? A Guide for Evaluating Coastal Community Resilience to Tsunamis and Other Hazards.” U.S. Indian Ocean Tsunami Warning System Program supported by the United States Agency for International Development and partners, Bangkok, Thailand. 144. [Coastal Community Resilience to Tsunamis and Other Hazards]

Goals \& Scope: This coastal community resilience (CRR) guide utilizes a holistic planning framework and benchmark scoring system to help reduce hazard impacts among vulnerable coastal communities. It is designed to guide communities, aid agencies, or private donors in conducting a rapid participatory planning process focused on identifying weaknesses and selecting strategies to reduce risks and recovery times.

\section{Framework Summary:}

- Focal areas: buildings, infrastructure, economics, health, other social systems, and natural systems

- Unit of analysis: tribes, communities, and ecosystems

- Total number of measures and indicators: 188

Development Process: The framework and associated benchmarks used in the guide were developed through a participatory process with inputs from numerous government and nongovernmental representatives, which includes focuses on emergency response, disaster recovery, and governance. Details and worksheets are provided on identifying local goals and scoring the benchmarks, collecting needed data, and communicating findings.

Definition of resilience: "Community resilience is the capacity of a community to adapt to and influence the course of environmental, social, and economic change." (Page 3-1) 
49. UNDP Drylands Development Centre (2014). "Community Based Resilience Analysis (CoBRA) Conceptual Framework and Methodology." Commissioned by UNDP Drylands Development Centre, Under the Framework of: Humanitarian Aid and Civil Protection Department of the European Commission's Drought Risk Reduction Action Plan. [CoBRA]

Goals \& Scope: The Community Based Resilience Analysis (CoBRA) framework and methodology enables the assessment of community resilience and the impact of specific community and household-level strategies on resilience. Focused on drought and disaster resilience in the dryland regions in the Horn of Africa, the tool is intended to follow a flexible, participatory process based in a series of facilitated community focus group meetings and key informant interviews.

\section{Framework Summary:}

- Focal areas: infrastructure, economics, other social systems, and natural systems

- Unit of analysis: communities

- Total number of measures and indicators: 39

Development Process: The tool was developed via a review of existing literature and frameworks, including both models that describe a systems approach to resilience and those that attempt to measure community resilience characteristics. Following initial development, the framework was refined using multiple iterations of expert feedback and pilot-testing.

Definition of resilience: "... an inherent as well as acquired condition achieved by managing risks over time at individual, household, community and societal levels in ways that minimize costs, build capacity to manage and sustain development momentum, and maximize transformative potential." (Page 3).

50. United Nations Office for Disaster Risk Reduction (2017). "Disaster Resilience Scorecard for Cities, Detailed Level Assessment." United Nations Office for Disaster Risk Reduction (UNDRR) [UNISDR Scorecard]

Goals \& Scope: The Disaster Resilience Scorecard for Cities is a flexible assessment method for local governments and used to develop strategies and monitor progression of Sendai Framework for Disaster Risk Reduction 2015-2030 goals and programs. The scorecard can be used at a variety of levels, from high-level summaries of current conditions to an in-depth review of current resilience, using flexible measures, weighting, and scoring options to fit local needs. Resulting scores are intended for internal use and are not comparable across cities. (Note: this entry was created using the above 2017 Assessment paper; the Inventory entry was based on a 2015 version of the document. See Inventory "references" tab for details). 


\section{Framework Summary:}

- Focal areas: buildings, infrastructure, economics, health, other social systems, and natural systems

- Unit of analysis: municipalities

- Total number of measures and indicators: 154

Development Process: The scorecard was based on an update of the UNDRR's Ten Essentials for Making Cities Resilient (UNDRR 2015), which was first developed as part of the 2005 Hyogo Framework for Action. These ten areas cover a broad array of topics that influence disaster resilience such as financial capacity, disaster preparation, and disaster response and recovery.

Definition of resilience: "Resilience as defined by the Sendai Framework is the ability of a system, community or society exposed to hazards to resist, absorb, accommodate, adapt too, transform and recover from the effects of a hazard in a timely and efficient manner, including through the preservation and restoration of its Essential basic structures and functions through risk management." (Page 3 ).

51. United Nations and International Strategy for Disaster Reduction (ISDR) (2007). "Hyogo Framework for Action 2005-2015: Building the Resilience of Nations and Communities to Disasters." Extract from the final report of the World Conference on Disaster Reduction (A/CONF.206/6). Geneva, Switzerland, International Strategy for Disaster Reduction (ISDR). [Hyogo]

Goals \& Scope: This document provides a workshop summary from the World Conference on Disaster Reduction in 2005. It provides high-level international strategy for addressing disasters by improving policy, identifying and reducing risks, and developing education efforts. Other vulnerabilities under consideration include urban planning, poverty, and climate variability.

\section{Framework Summary:}

- Focal areas: buildings, infrastructure, economics, and other social systems

- Unit of analysis: communities

- Total number of measures and indicators: 42

Development Process: Summary of proceedings from the World Conference on Disaster Reduction, which convened to review The Yokohama strategy. It provides a high-level strategy discussion without focus on specific indicators of resilience.

Definition of resilience: "The capacity of a system, community or society potentially exposed to hazards to adapt, by resisting or changing in order to reach and maintain an acceptable level of functioning and structure This is determined by the degree to which the social system is capable 
of organizing itself to increase this capacity for learning from past disasters for better future protection and to improve risk reduction measures (UN/ISDR. Geneva, 2004)." (Page 4).

52. United Nations Development Programme (UNDP) (2004). “A Global Report: Reducing Disaster Risk, a Challenge for Development.” New York, NY, United National Development Programme, Bureau for Crisis Prevention and Recovery. [UNDP DRI]

Goals \& Scope: This report details patterns and linkages between development and disaster risks, and presents a pilot Disaster Risk Index (DRI). The index calculates the relative vulnerability of countries to earthquakes, tropical cycles, and floods (focused on mortality likelihood), and identifies associated risk factors. The report concludes with an agenda of emerging research, data, and policy needs for international disaster risk reduction.

\section{Framework Summary:}

- Focal areas: buildings, infrastructure, economics, health, other social systems, and natural systems

- Unit of analysis: countries

- Total number of measures and indicators: 65

Development Process: Focused at a national level, the Risk Index was developed utilizing 1980 - 2000 mortality data in a global disaster database, as well as socio-demographic, economic, health, and other data from various sources. Data was aggregated and transformed, and regression analyses were used to identify which vulnerability factors were most associated with the average risk of death during a large or medium-sized disaster.

Definition of resilience: "The capacity of a system, community or society to resist or to change in order that it may obtain an acceptable level in functioning and structure. This is determined by the degree to which the social system is capable of organizing itself, and the ability to increase its capacity for learning and adaptation, including the capacity to recover from a disaster." (Page 136).

53. United Nations University - Institute for Environment and Human Security (UNU-EHS) (2014). “WorkRiskReport 2014." Bonn, Germany, United Nations University - Institute for Environment and Human Security (UNU-EHS). [WorldRiskIndex]

Goals \& Scope: The WorldRiskIndex is a score estimating the vulnerability of a Country's population to extreme natural events, focused on both hazard exposure and population-level susceptibility. It is intended to be a quickly comparable, high-level indicator of natural hazard exposure and vulnerability between countries. 


\section{Framework Summary:}

- Focal areas: buildings, infrastructure, economics, health, other social systems, and natural systems

- Unit of analysis: metropolitan areas and countries

- Total number of measures and indicators: 73

Development Process: The Index is calculated by considering four main areas: the hazard exposure of a country and its vulnerability to impacts via susceptibility, coping capacities, and adaptive capacities. Among the four focus areas, scores were calculated based on 28 indicators utilizing internationally available public data, which are weighted and combined to create the overall score.

Definition of resilience: None provided.

54. United States Agency for International Development (USAID) (2013). "THE RESILIENCE AGENDA: Measuring Resilience in USAID.” USAID. [Measuring Resilience in USAID]

Goals \& Scope: This document provides a short set of indicators focused on livelihood resilience, as agreed upon by the Horn of Africa and Sahel Joint Planning Cells to assess their development investments in the region.

\section{Framework Summary:}

- Focal areas: economics, health, and other social systems

- Unit of analysis: individuals, households, tribes, and communities

- Total number of measures and indicators: 63

Development Process: The selected indicators of resilience are focused on livelihood outcomes and include reduction in humanitarian assistance needs, depth of poverty, and the presence of hunger and malnutrition. These domains were developed based on a 2008 FAO resilience framework, and Feed the Future/Food for Peace (FTF/FFP) baseline and secondary survey data.

Definition of resilience: "USAID defines resilience as the ability of people, households, communities, countries and systems to mitigate, adapt to and recover from shocks and stresses in a manner that reduces chronic vulnerability and facilitates inclusive growth." (Page 1). 
55. Vaitla, B., G. Tesfay, M. Rounseville and D. Maxwell (2012). "Resilience and Livelihoods Change in Tigray, Ethiopia.” Somerville MA, Feinstein International Center, Tufts University. [Resilience and Livelihoods Change]

Goals \& Scope: This study and corresponding measurement tool assess livelihood change and household wellbeing of communities in Ethiopia. The measure utilized seven indicators focused on topics such as household food security, presence of illness, and family income and assets. Findings from the study identify factors predictive of resilience to food insecurity and other shocks, and the measure contributes to policy and humanitarian program evaluation efforts.

\section{Framework Summary:}

- Focal areas: infrastructure, economics, health, and other social systems

- Unit of analysis: individuals and households

- Total number of measures and indicators: 67

Development Process: A conceptual framework was first developed by literature review and consideration of the key factors influencing livelihoods and household wellbeing in the study context. Scale and data collection then consisted of a series of survey questions, administered to households twice yearly (in the postharvest and hungry seasons).

Definition of resilience: "Resilience is the ability of an individual, a household, a community or an institution to withstand a shock or setback of some type and recover, or "bounce back," after a setback. As such, it implies the ability to cope with adversity by adapting, learning and innovating." (Page 3).

56. Washington State Emergency Management Council: Seismic Safety Committee (2012). "Resilient Washington State: A Framework for Minimizing Loss and Improving Statewide Recovery after an Earthquake.” Olympia, WA, Washington State Seismic Safety Committee. [Resilient Washington]

Goals \& Scope: This report was developed by the state of Washington to serve as a guide for earthquake risk reduction actions and policies. It includes a vulnerability assessment of four main sectors (critical services, utilities, transportation, and housing and economic development), and corresponding recovery goals and policy recommendations. Recovery goals include health and safety, property protection, economic security, environmental quality, and community continuity.

\section{Framework Summary:}

- Focal areas: buildings, infrastructure, economics, health, other social systems, and natural systems

- Unit of analysis: state

- Total number of measures and indicators: 104 
Development Process: Through a series of meetings, workshops, and discussions held over two years, subject matter experts and stakeholders in the local, government, university, and business sectors assessed earthquake impacts and resilience in four main areas: critical services, utilities, transportation, and housing and economic development. First, working groups were given a severe earthquake scenario and conducted a vulnerability assessment of the sectors' estimated recovery capacity given current conditions. Groups then identified goals for desired recovery timeframes, with recommendations for reaching recovery and resilience goals.

Definition of resilience: "A resilient state is one that maintains services and livelihoods after an earthquake. In the event that services and livelihoods are disrupted, recovery occurs rapidly, with minimal social disruption, and results in a new and better condition." (Page 1). 


\section{Impact and Conclusions}

This annotated bibliography provides a summary of the 56 source documents ${ }^{2}$ used to develop the NIST Resilience Indicator Inventory dataset (see: link) (Dillard et al. 2018b). It documents the various theoretical and methodological approaches in the measurement of community resilience, providing a summary of their goals and development methods, their associated indicators and measures, as well as the definitions of resilience used. Coupled with the Indicator Inventory itself, a data paper summarizing the Inventory contents, and other community resilience assessment tools (see the NIST Community Resilience Group products page for more details: link), these products provide a resource for groups intending to use existing frameworks for tailoring a methodology to assess their community's resilience.

This resource can be utilized for one of several purposes. First, by providing a summary of previous efforts in community resilience measurement, this bibliography can be used by practitioners to learn more about available assessment and decision support tools. In particular, using the annotated bibliography in combination with the Inventory will expand the frame of reference for the types of data and approaches available for measuring resilience in similar contexts or communities. As the source documents include frameworks for measuring resilience for various community types, hazards, scopes, and goals, this resource can provide guidance on available tools and may support the identification of planning resources.

Second, this resource is valuable to other researchers interested in community resilience topics and metrology. The synthesis of frameworks, development methods, indicators, and approaches presented provides a basis for assessment development, comparison, and validation efforts. For example, a review of the document's development methods can be used to understand common methods utilized within the field of community resilience assessment. Or, a selection of frameworks on a specific topic, such as drought resilience, could form the basis of a literature review. The definitions of resilience can be used by researchers seeking to better understand or conduct additional research such as comparing definitions of resilience among different disciplines.

Lastly, this work will inform several ongoing efforts at NIST related to community resilience decision support and measurement. Specifically, this work supports ongoing efforts to systematically compare these approaches, and to inform the development of a theoretically and empirically based community resilience assessment methodology.

\footnotetext{
${ }^{2}$ In some cases, the source document used in the indicatory inventory had been taken down or updated and could not be found online at the time of creating this annotated bibliography. In these cases, a document with as close a match as possible to the original was used. These cases are noted in the entries above.
} 


\section{Acknowledgments}

The authors would like to acknowledge the generous support of our internal NIST reviewers for their comments and recommendations. The NIST authors also recognize the efforts Frank Lavelle, Charles Goodhue, and the team of researchers with Applied Research Associates, Inc. and Eastern Research Group, Inc. who worked on the NIST Inventory of Community Resilience Indicators \& Assessment Frameworks. Finally, the authors thank the field of community resilience researchers and practitioners who have contributed to this important field of work. 


\section{References}

ARUP International Development. 2016. "City Resilience Index: Understanding and Measuring City Resilience.” London, UK.

ARUP International Development and International Federation of Red Cross and Red Crescent Societies. 2011. "Characteristics of a Safe and Resilient Community: Community Based Disaster Risk Reduction Study". Geneva, Switzerland. International Federation of Red Cross and Red Crescent Societies.

Bakkensen, L.A., Fox-Lent, C., Read, L.K. and Linkov, I. 2017. "Validating Resilience and Vulnerability Indices in the Context of Natural Disasters". Risk Analysis, 37: 982-1004. doi:10.1111/risa.12677.

Bates, F. L. and W. G. Peacock. 1992. "Measuring Disaster Impact on Household Living Conditions: The Domestic Assets Approach." International Journal of Mass Emergencies and Disasters 10: 133-160.

Beccari, B. 2016. "A Comparative Analysis of Disaster Risk, Vulnerability and Resilience Composite Indicators". PLOS Currents Disasters Edition 1. doi: 10.1371/currents.dis.453df025e34b682e9737f95070f9b970.

Belcher, J. C. 1972. “A cross-cultural household level-of-living scale”. Rural Sociology, 37(2), 208.

Béné, C., Al-Hassan, R. M., Amarasinghe, O., Fong, P., Ocran, J., Onumah, E., ... \& Mills, D. J. 2016. "Is resilience socially constructed? Empirical evidence from Fiji, Ghana, Sri Lanka, and Vietnam". Global Environmental Change, 38, 153-170.

Béné, C., Frankenberger, T., \& Nelson, S. 2015. "Design, Monitoring and Evaluation of Resilience Interventions: Conceptual and Empirical Considerations". IDS Working Paper 459, Institute of Development Studies. 23 p.

Bene, C., T. Frankenberger, M. Langworthy, M. Mueller and S. Martin. 2016. "The Influence of Subjective and Psycho-social Factors on People's Resilience: Conceptual Framework and Empirical Evidence.” Technical Report Series No. 2: Strengthening the Evidence Base for Resilience in the Horn of Africa, A joint International Livestock Research Institute (ILRI) and TANGO International publication.

Berkes, F. and C. S. Seixas. 2005. "Building Resilience in Lagoon Social-Ecological Systems: A Local-level Perspective." Ecosystems 8: 967-974.

Brooks, N., S. Anderson, I. Burton, S. Fisher, N. Rai and I. Tellam. 2013. "An Operational Framework for Tracking Adaptation and Measuring Development (TAMD).” IIED Climate Change Working Paper Series: Climate Change Working Paper No. 5. 
Canadian Centre for Community Renewal. 2000. "The Community Resilience Manual: A Resource for Rural Recovery \& Renewal." British Columbia, Canada. Canadian Centre for Community Renewal.

Canterbury District Health Board. 2016. "Canterbury Wellbeing Index 2016." Christchurch, New Zealand.

Cardona, O. D., Hurtado, J. E., Duque, G., Moreno, A., Chardon, A. C., Velasquez, L. S., \& Prieto, S. D. 2003. "The notions of disaster risk: conceptual framework for integrated management." Information and indicators program for disaster risk management. InterAmerican Development Bank, Manizales.

Cardona, O. 2005. "Indicators of disaster risk and risk management: Main technical report. Washington, DC.” Inter-American Development Bank.

CGIAR Research Program on Water Land and Ecosystems (WLE). 2014. "Ecosystem Services and Resilience Framework." Colombo, Sri Lanka. CGIAR Research Program on Water, Land and Ecosystems, International Water Management Institute (IWMI).

Chandra, A., J. Acosta, S. Stern, L. Uscher-Pines, M. V. Williams, D. Yeung, J. Garnett and L. S. Meredith. 2011. "Building Community Resilience to Disasters: A Way Forward to Enhance National Health Security." Santa Monica, CA. RAND Corporation with sponsorship by the U.S. Department of Health and Human Services.

Choptiany, J., B. Graub, S. Phillips, D. Colozza and J. Dixon. 2015. "Self-Evaluation and Holistic Assessment of Climate Resilience of Farmers and Pastoralists (SHARP).” Rome, Italy. Food and Agriculture Organization of the United Nations (FAO).

Clavin, C. 2020. "Community Resilience Planning Guide for Buildings and Infrastructure Systems: A Playbook." NIST Special Publication (NIST SP) 1190GB-16. Gaithersburg, MD. National Institute of Standards and Technology. doi:/10.6028/NIST.SP.1190GB-16.

Clavin, C., D'Abreau, A., \& Walpole, E.H. 2020. "Resilience, Adaptation, and Sustainability Plan Assessment Methodology: An Annotated Bibliography." NIST Technical Note 2117. Gaithersburg, MD. National Institute of Standards and Technology. doi:/10.6028/NIST.TN.2117.

Community and Regional Resilience Institute. 2011. "Community Resilience System Initiative (CRSI) Steering Committee final report: A roadmap to increased community resilience." Community and Regional Resilience Institute. 
Constas, M. A. and C. B. Barrett. 2013. "Principles of Resilience Measurement for Food Insecurity: Metrics, Mechanisms, and Implementation Issues." Expert Consultation on Resilience Measurement Related to Food Security. Rome, Italy. Food and Agricultural Organization and World Food Program.

Cutter, S. 2016. "The landscape of disaster resilience indicators in the USA." Natural Hazards 80: 741-758.

Cutter, S. L., K. D. Ash and C. T. Emrich. 2014. "The Geographies of Community Disaster Resilience." Global Environmental Change 29: 65-77.

Cutter, S. L., B. J. Boruff and W. L. Shirley. 2003. "Social Vulnerability to Environmental Hazards (SoVI)." SOCIAL SCIENCE QUARTERLY - Southwestern Social Science Association 84(2): 242-261.

DFID-funded International Climate Fund (ICF). 2014. "Methodology for Reporting Against KP14 - Number of People Whose Resilience Has Been Improved as a Result of Project Support."

Dillard, M. K. 2018a. "Developing an Assessment Methodology for Community Resilience". In RESILIENCE: The 2nd International Workshop on Modeling of Physical, Economic and Social Systems for Resilience Assessment, Vol. 2.

Dillard, M. K. 2018b. "Inventory of Community Resilience Indicators \& Assessment Frameworks". Gaithersburg, MD. National Institute of Standards and Technology. doi: https://doi.org/10.18434/mds2-2297.

Dillard, M. K., T. L. Goedeke, S. Lovelace and A. Orthmeyer. 2013. "Monitoring Well-being and Changing Environmental Conditions in Coastal Communities: Development of an Assessment Method." NOAA Technical Memorandum NOS NCCOS 174. Silver Spring, MD. NOAA National Centers for Coastal Ocean Science (NCCOS).

Edgemon, L., Freeman, C., Burdi, C., Trail, J., Marsh, K., Pfeiffer, K. 2018. “Community Resilience Indicator Analysis: County-Level Analysis of Commonly Used Indicators From Peer-Reviewed Research.”

Elasha, B. O., N. G. Elhassan, H. Ahmed and S. Zakieldin. 2005. "Sustainable livelihood approach for assessing community resilience to climate change: case studies from Sudan.” AIACC Working Paper No. 17 August 2005, Assessments of Impacts and Adaptations of Climate Change (AIACC). 
Fisher, R.E., Bassett, G.W., Buehring, W.A., Collins, M.J., Dickinson, D.C., Eaton, L.K., Haffenden, R.A., Hussar, N.E., Klett, M.S., Lawlor, M.A. and Millier, D.J. 2010. "Constructing a resilience index for the enhanced critical infrastructure protection program.” (No. ANL/DIS-10-9). Argonne, IL. Argonne National Lab.(ANL), Decision and Information Sciences.

Folke C, Colding J, Berkes F. 2003. "Synthesis: building resilience and adaptive capacity in social-ecological systems". In: Berkes F, Colding J, Folke C, Eds. Navigating socialecological systems: Building resilience for complexity and change. Cambridge: Cambridge University Press. p 352-87

Frankenberger, T., T. Spangler, S. Nelson and M. Langworthy. 2012. "Enhancing Resilience to Food Security Shocks in Africa." TANGO International.

Hegney, D., H. Ross, P. Baker, C. Rogers-Clark, C. King, E. Buikstra, A. Watson-Luke, K. McLachlan and L. Stallard. 2008. "Building Resilience in Rural Communities: Toolkit." Toowoomba, Queensland, Australia. University of Queensland and University of Southern Queensland.

Inter-Agency Standing Committee. 2005. "IASC In-Country Team Self-Assessment Tool for Natural Disaster Response Preparedness."

Institute of Governmental Studies: The University of California Berkeley. 2017. "Resilience Capacity Index (RCI).” Building Resilient Regions. Retrieved 8/7/2017, from: http://brr.berkeley.edu/rci/.

Keating, A., K. Campbell, R. Mechler, E. Michel-Kerjan, J. Mochizuki, H. Kunreuther, J. Bayer, S. Hanger, I. McCallum, L. See, K. Willigies, A. Atreya, W. Botzen, B. Collier, J. Czajkowski, S. Hochrainer and C. Egan. 2014. "Operationalizing Resilience against Natural Disaster Risk: Opportunities, Barriers, and a Way Forward.” Zurich, Switzerland. Zurich Flood Resilience Alliance.

Kwasinski A, J Trainor, R Francis, C Chen, FM Lavelle. 2017. "Further Development of a Conceptual Framework for Assessing Resilience at the Community Scale.” NIST Grants/Contractor Reports 17-013. Gaithersburg, MD. National Institute of Standards and Technology.

Kwasinski, A., Trainor, J., Wolshon, B., \& Lavelle, F.M. 2016. “A Conceptual Framework for Assessing Resilience at the Community Scale. NIST GCR 16-001.” Gaithersburg, MD. National Institute of Standards and Technology.

Lavelle, F.M., Ritchie, L.A., Kwasinski, A., Wolshon, B. 2015. “Critical Assessment of Existing Methodologies for Measuring or Representing Community Resilience of Social and Physical Systems, NIST GCR 15-1010.” Gaithersburg, MD. National Institute of Standards and Technology. 
Mayunga, J. S. 2007. "Understanding and Applying the Concept of Community Disaster Resilience: A capital-based approach." Summer academy for social vulnerability and resilience building, 1(1), 1-16.

Miles, S. B. and S. E. Chang. 2011. "ResilUS: A Community Based Disaster Resilience Model." Cartography and Geographic Information Science 38(1): 5-21.

Miller, K. K., A. Johnson and B. Dabson. 2016. WORKING PAPER IPP/071: "Measuring Resilience and Vulnerability in U.S. Counties". University of Missouri Institute of Public Policy: Harry S Truman School of Public Affairs.

National Preparedness Training Center - University of Hawaii. 2011. "Coastal Community Resilience: Building Resilience from the Inside Out (CCR)". FEMA, US Department of Homeland Security National Training and Education Division: 317-333.

NOAA National Centers for Environmental Information (NCEI) U.S. Billion-Dollar Weather and Climate Disasters (2021). https://www.ncdc.noaa.gov/billions/, doi: 10.25921/stkw$7 \mathrm{w} 73$

Norris, F. H., S. P. Stevens, B. Pfefferbaum, K. F. Wyche and R. L. Pfefferbaum. 2007. "Community Resilience as a Metaphor, Theory, Set of Capacities, and Strategy for Disaster Readiness." American Journal of Community Psychology 41: 127-150.

O’Connell, D., Walker, B., Abel, N., Grigg, N. 2015. “The Resilience, Adaptation and Transformation Assessment Framework: From Theory to Application.” Commissioned by the Scientific and Technical Advisory Panel (STAP) of the Global Environmental Facility (GEF).

Oregon Seismic Safety Policy Advisory Commission (OSSPAC). 2013. “The Oregon Resilience Plan: Reducing Risk and Improving Recovery for the Next Cascadia Earthquake and Tsunami." Salem, OR.

Peacock, W.G., Brody, S.D., Seitz, W.A., Merrell, W.J., Vedlitz, A., Zahran, S., Harriss, R.C. and Stickney, R. 2010. "Advancing resilience of coastal localities: Developing, implementing, and sustaining the use of coastal resilience indicators: A final report." Hazard Reduction and Recovery Center. 1-148.

Pfefferbaum, R.L., Pfefferbaum, B., Van Horn, R.L., Klomp, R.W., Norris, F.H. and Reissman, D.B. 2013. "The communities advancing resilience toolkit (CART): An intervention to build community resilience to disasters." Journal of public health management and practice, 19(3), pp.250-258.

Prevention Institute. 2004. "A Community Approach to Address Health Disparities: Toolkit for Health \& Resilience in Vulnerable Environments (THRIVE)." Washington, DC. Office of Minority Health, U.S. Department of Health and Human Services. 
Redman, C. L., J. Morgan Grove and L. H. Kuby. 2004. "Integrating Social Science into the Long-Term Ecological Research (LTER) Network: Social Dimensions of Ecological Change and Ecological Dimensions of Social Change." Ecosystems 7(2): 161-171. [Long-Term Ecological Research Network

Rose, A.Z. 2009. "A framework for analyzing the total economic impacts of terrorist attacks and natural disasters." Journal of Homeland Security and Emergency Management, 6(1).

San Francisco Planning and Urban Research Association (SPUR). 2009. "The Resilient City: Defining What San Francisco Needs from its Seismic Mitigation Policies." San Francisco, CA.

Semper, T. T., D. L. Swann, R. Emmer, S. H. Sempier and M. Schneider. 2010. "Coastal Community Resilience Index: A Community Self-Assessment.” MASGP-08-014: National Oceanic and Atmospheric Administration (NOAA).

Sharifi, A. 2016. "A critical review of selected tools for assessing community resilience." Ecological Indicators 69: 629-647.

The International Federation of Red Cross and Red Crescent Societies. 2014. "IFRC Framework for Community Resilience." Geneva, Switzerland. International Federation of Red Cross and Red Crescent Societies.

Twigg, J. 2007. "Characteristics of a Disaster-resilient Community: A Guidance Note, Version 1 (for field testing)." DFID Disaster Risk Reduction Interagency Coordination Group.

Twigg, J. 2009. "Characteristics of a Disaster-Resilient Community: A Guidance Note, Version 2." London, UK. University College of London.

Tyler, S., M. Keller, D. Swanson, L. Bizikova, A. Hammill, A. N. Zamudio, M. Moench, A. Dixit, R. G. Flores, C. Heer, D. González, A. R. Sosa, A. M. Gough, J. L. Solórzano, C. Wilson, X. Hernandez and S. Bushe. 2013. "IISD Report: Climate Resilience and Food Security: A Framework for Planning and Monitoring." Winnipeg, Manitoba, Canada. International Institute for Sustainable Development.

Tyler, S., Nugraha, E., Nguyen, H.K., Van Nguyen, N., Sari, A.D., Thinpanga, P., Tran, T.T. and Verma, S.S. 2016) "Indicators of urban climate resilience: A contextual approach." Environmental science \& policy, 66. 420-426.

UNDP Drylands Development Centre. 2014. "Community Based Resilience Analysis (CoBRA) Conceptual Framework and Methodology." Commissioned by UNDP Drylands Development Centre, Under the Framework of: Humanitarian Aid and Civil Protection Department of the European Commission's Drought Risk Reduction Action Plan. 
United Nations Office for Disaster Risk Reduction. 2017. "Disaster Resilience Scorecard for Cities, Detailed Level Assessment.” United Nations Office for Disaster Risk Reduction (UNDRR).

U.S. Department of Homeland Security. 2016. "Mitigation Framework Leadership Group (MitFLG) Draft Concept Paper: Draft Interagency Concept for Community Resilience Indicators and National-Level Measures." Washington, DC. U.S. Department of Homeland Security.

U.S. Indian Ocean Tsunami Warning System Program. 2007. "How Resilient Is Your Coastal Community? A Guide for Evaluating Coastal Community Resilience to Tsunamis and Other Hazards." U.S. Indian Ocean Tsunami Warning System Program supported by the United States Agency for International Development and partners.144.

United Nations and International Strategy for Disaster Reduction (ISDR). 2007. "Hyogo Framework for Action 2005-2015: Building the Resilience of Nations and Communities to Disasters" Extract from the final report of the World Conference on Disaster Reduction (A/CONF.206/6). Geneva, Switzerland. International Strategy for Disaster Reduction (ISDR).

United Nations Development Programme (UNDP). 2004. "A Global Report: Reducing Disaster Risk, a Challenge for Development.” New York, NY. United National Development Programme, Bureau for Crisis Prevention and Recovery.

United Nations University - Institute for Environment and Human Security (UNU-EHS). 2014. "WorkRiskReport 2014." Bonn, Germany. United Nations University - Institute for Environment and Human Security (UNU-EHS).

United States Agency for International Development (USAID). 2013. "THE RESILIENCE AGENDA: Measuring Resilience in USAID." USAID.

Vaitla, B., G. Tesfay, M. Rounseville and D. Maxwell. 2012. "Resilience and Livelihoods Change in Tigray, Ethiopia." Somerville MA. Feinstein International Center, Tufts University.

Washington State Emergency Management Council: Seismic Safety Committee. 2012. "Resilient Washington State: A Framework for Minimizing Loss and Improving Statewide Recovery after an Earthquake.” Olympia, WA. Washington State Seismic Safety Committee. 